\title{
Impact of service rates and base station switching granularity on energy consumption of cellular networks
}

\author{
Josip Lorincz ${ }^{1 *}$, Antonio Capone ${ }^{2}$ and Dinko Begusic ${ }^{1}$
}

\begin{abstract}
Over the last two decades we have witnessed significant growth of the cellular network energy consumption caused by a rapid increase in the number of mobile users and data volumes. This is contributed to by a tenfold increase of data rates every 5 years, and such a trend in up growth of energy consumption will continue with the introduction of a new throughput demanding services. Hence, development of new energy-saving techniques and estimation of the influence on energy savings when ensuring different service rates are the focus of this article. For the purpose of reducing cellular network energy consumption, this article proposes a new approach to energy-efficient management of network resources. The energy-efficient management is based on adaptive changes of on/off states of a complete base station (BS) site in accordance with the traffic pattern variations. Besides adaptations to the temporal traffic variations, the BS can adapt capacity to the spatial traffic variations through dynamic scaling of transmitted power according to capacity demand. We formulate the problem of energy-efficient management as a binary integer programming problem dedicated to energy consumption minimization of a complete network. Proposed methodology is simulated on a set of real size Universal Mobile Telecommunications System network instances consisting of different radio propagation environments. In addition, this article analyzes the influence on the energy savings potential of BSs switching granularity. Obtained results show that the proposed optimization approach offers significant reductions in the network energy consumption while preserving the most important QoS constraints like full area coverage and guaranteed service rates.
\end{abstract}

Keywords: Green, Energy, Wireless, Mobile, Cellular, Management, Switching, Base station, Power, Network, Optimization, Rate, UMTS

\section{Introduction}

Fast growth of wireless cellular networks in the past decades raises a critical problem of energy consumed by network equipment. The number of mobile devices in cellular networks explosively increases, and by 2013 mobile devices will surpass fixed computers (PCs) as the most common web access device [1]. This imposes deployment of additional network infrastructures, primarily more base stations (BSs), which significantly increases energy consumption of the whole network [2]. On the other hand, it is expected that data volume of Information and Communication Technologies (ICT) increases

\footnotetext{
* Correspondence: josip.lerinc@fesb.hr

${ }^{1}$ FESB-Faculty of Electrical Engineering, Mechanical Engineering and Naval Architecture, University of Split, Croatia, R. Boskovica b.b, Split 21000, Croatia Full list of author information is available at the end of the article
}

approximately by a factor of ten every 5 years. This triggers energy consumption upgrowth on yearly bases for $16-20 \%$ [3]. Considering only the sector of mobile communications, it will contribute with $15-20 \%$ to the entire ICT sector energy consumption, and $0.3-0.4 \%$ of the annual world carbon dioxide $\left(\mathrm{CO}_{2}\right)$ footprint [4]. All mentioned results in both academia and industry reach a consensus on the growing need to develop more energy-efficient wireless access networks. In addition, new services which are more throughput intensive, like multimedia and data services, begin dominating in practical usage. For cellular networks, satisfying the tenfold increase of data rates every 5 years comes with the cost of high-energy consumption [3]. Because of this, investigating the influence of the transition to higher data rates on network energy consumption becomes imperative. 
From the perspective of cellular network operators, increasing network energy efficiency is not only a matter of being green and responsible, but also an important economical issue since reducing energy consumption translates to lower operational expenditures. It has been estimated that the radio access part of a cellular network, more specifically the BS, is a major energy consumer [5]. As pointed out in [6], energy consumption of the BS contributes to more than $55 \%$ of total cellular network energy consumption. In this article, therefore, we focus on energy-efficient operation of the cellular BS. Increasing energy efficiency of the BS can be accomplished through a holistic approach considering improvements on: component, link, and network levels [7]. On the component level, special attention is dedicated to improving power amplifier efficiency [8], minimizing feeder losses [9], and introducing novel air cooling approaches [10]. Energy saving potential on the link level can be found in link adaptation methods [11] and discontinuous transmission realized through BS sleep modes [12]. Although component and link levels will be important contributors to "greener" wireless cellular networks, we believe that the network level approach can offer the highest energy savings. This is because the component level approach limits improvements to individual components of the BS only. On the other hand, the link level approach, based on turning off some of the components like radio transceivers on the BS during low traffic periods, provides some relief, which is still not sufficient. For significant energy savings, the network level approach based on the dynamic management of BS resources seems to be the most promising [7]. This approach allows the system to shut down an entire BS and transfer the corresponding traffic to a neighboring BS during the periods of low user activity.

In this article, we propose such an energy-efficient management scheme and as an important element we emphasize possible implementation in already deployed cellular networks. Such a possibility lies in a conservative approach to the coverage and capacity planning of analyzed cellular networks. In practical scenarios, cellular coverage is characterized with multiple overlapping layers of cells while capacity has been estimated for accommodating the highest traffic load during peak hours. However, the traffic load in cellular networks can have spatial and temporal fluctuations due to user mobility and daily variations of user activity. To save energy, during the periods of low user activity, it is possible to switch off unutilized or underutilized BSs without compromising coverage and service quality. Therefore, we propose a model that takes into account slow temporal variations of traffic through dynamic switching on and off of complete BS sites (BSSs) according to the daily traffic variations.
In addition, to consider highly dynamic spatial traffic fluctuations, we assume an energy-efficient network management system which can adaptively scale BS transmitted (Tx) power according to the capacity demands. The proposed site capacitating concept adaptively increases or decreases capacity and coverage of the BS in the case of transmission at higher or lower Tx power levels. Such a concept can be implemented since analyses have been performed on a set of real size Universal Mobile Telecommunications System (UMTS) networks based on Wideband Code Division Multiple Access (WCDMA) technology. By knowing that the capacity of a WCDMA BS directly depends on Tx power, and the Tx power of BSs influence on total network energy consumption, it is possible to estimate how the introduction of higher service data rates will influence on network energy consumption. In addition, the prevalence of dynamic BSs switching between on and off states is another issue that has influence on the energy-saving potential of a complete cellular network. Accordingly, in this article we perform analyses for three distinct switching approaches, differing in time discretization of a real traffic pattern. In these analyses, we also take into account differences between the traffic patterns of working and weekend days.

Hence, effectiveness of the proposed energy-efficient network management has been estimated through development of an optimization model, using principles of integer linear programming (ILP). The model minimizes monthly energy consumption of complete UMTS network, also preserving full network coverage and a fixed service rate. The main contribution of this article is the presentation of the influence of the BSs switching granularities and the guaranteed service rates on network energy consumption. Moreover, the obtained optimization results allow us to understand quantitatively the scope for potential energy savings.

The outline of the article is organized as follows: in Section 2, we give an overview of the latest research efforts dedicated to the energy-efficient resource management of wireless access networks. Description of a path loss model used for coverage planning of different radio propagation environments has been presented in Section 3. Section 4 explains the structure of the UMTS network instances used for simulating the proposed resource management approach. Also in Section 4 approximation of the traffic pattern is explained. Since coverage and capacity planning have directly been related in UMTS networks, Section 5 deals with site capacitating in order to estimate the correlation between BS capacity and the level of Tx power. Mathematical formulation of the optimization problem tending to minimize network energy consumption has been explained in Section 6 . In addition, description of a software solution developed for the generation of the analyzed network instances is 
given also in Section 6. In Section 7, obtained optimization results in terms of energy savings have been discussed. Section 8 eventually concludes the article.

\section{Related work}

Cognition related to high energy consumption of mobile cellular networks contributed a non-negligible amount of greenhouse gas emissions, encouraging broad research efforts dedicated to increasing energy efficiency of the radio part of wireless access networks. In this section, we give a brief overview of these efforts, focusing primarily on energy-saving techniques realized through dynamic radio resource management based on the traffic statistics. To the best of the authors' knowledge, we have proposed for the first time, in $[13,14]$, a binary integer programming (BIP) optimization approach focused on energy consumption minimization of a complete large-scale wireless local area network (WLAN). Results showing significant energy savings of WLANs have been extended in $[15,16]$, through development of novel, practically implementable heuristic algorithms based on greedy and local search methods.

On the other hand, novel solutions contributing to the energy savings of wide area cellular access networks have been reported in [17-23]. Chiaraviglio et al. [17] show the possibility of switching off some cells and Node B's in the UMTS network during low-traffic periods, while still guaranteeing quality of service constraints in terms of blocking probability and electromagnetic exposure limits. Obtained results have been extended in [18], with the investigation of possible energy reductions of a cellular network by reducing the number of active cells of different topologies during the periods in which they are underutilized. Although authors claim energy savings potential of up to $30 \%$, results have been obtained for small and isolated example cases. Analyses performed in [19], on a somewhat larger network example, exploits the idea of switching off cells while neighboring active cells adopt an antenna tilt at times of low network load. Although obtained for cells arranged regularly in the two concentric circles, results clearly indicate that network coverage can be kept intact when the individual cell of one or three-sector site is switched off. This article additionally gives an overview of short-term energy saving mechanisms based on micro-sleep and dynamic spectrum reduction. Even broader overviews of relevant challenges in the area of green cellular networks and solutions considering: power control, operator's cooperation, heterogeneous cells, relay techniques, granularity control, etc., have been discussed in [20]. In addition, using real data traces from the part of the real urban area network, authors emphasize promising potential in terms of power saving that one can expect by turning off BSs during low traffic periods. The studies of $[21,22]$ are of particular interest since both provide ILP formulations of energy optimization problems, confirming that mathematical optimization methods have extremely been valuable tools for modeling possible energy-efficient solutions in cellular networks. The study [21] concludes that practical real-time user-cell reallocation may be faceable and may bring significant energy savings, while the study [22] points out that BS density and the mean and variance of the traffic profiles have been dominant factors in determining the amount of energy savings. The study [23] proposes the concept of cell zooming, which enables adaptive adjustment of the cell size according to the traffic load. Authors emphasize that cell zooming, besides solving the problem of traffic imbalance, can also reduce energy consumption of the cellular network. Due to the need for more throughputs in wireless cellular networks, Videv et al. [24] develop a scheduler which aims to solve the problem of energy-efficient resource allocation in orthogonal frequency division multiple access cellular systems. Huang et al. [25] propose energy-efficient semistatic power control and a link adaptation scheme for UMTS (HSDPA) networks. The proposed scheme can determine the most energy-efficient modulation and coding schemes levels and transmit power at the Node B. Finally, a comprehensive overview and classification of the research approaches based on component level, cell layout adaptation with coverage extension and resource management are presented as in [26].

According to the research results presented in the mentioned studies, it is obvious that an energy-efficient approach based on a dynamic adaptation of network resources to traffic pattern can bring significant energy savings. Therefore, it is necessary to investigate such potential more deeply, especially on real size networks having the macro BSSs allocated inside distinct propagation areas, such as urban-dense, urban, or suburban. In the light of the permanent increase of guaranteed service rates, absence of valuable research results addressing the influence of such an increase on the network energy consumption represents reasonable grounds for deeper investigation. In addition, temporal granularity of control is an important issue in dynamic BS switching and this article, as far as we are aware, gives, for the first time, insights into this issue.

\section{Coverage planning}

One of the most basic considerations in radio channel modeling is determining the morphology that the analyzed network models will be applied to. This leads to general assumptions being made for an analyzed service area (SA) that corresponds to a broader region of a medium sized city. In order to consider such a morphology case, we assume three different morphology categories classified as urban-dense, urban, and suburban 
(rural) coverage areas (CAs). Figure 1a,b presents anticipated virtual borders of each CA for the lowest and highest Tx power levels of installed equipment at each coverage site (CS), respectively. Each type of CA is categorized according to density of obstacles assumed on the radio propagation path. It may seem obvious that classifying CAs according to these morphologies is rather ambiguous because the geographic size will never have regular CA borders in reality. Nevertheless, we assume such classification and bordering in order to more realistically model real radio propagation environment of a medium city, which can typically be characterized with decreasing obstacle density in direction from a center to a border city region.

In order to correctly and efficiently model the propagation environment of a UMTS network, we utilize the path loss model commonly used for modeling propagation environments in macro cells of the $2 \mathrm{G}$ and $3 \mathrm{G}$ networks known as the Hata (Okumura-Hata) model $[27,28]$. Actually, for estimating radio coverage of BSSs in analyzed UMTS networks, we exploit extended version of the Okumura-Hata model known as COST-231, which extends Hata's model to frequencies of $2 \mathrm{GHz}$.

Maximal coverage distances in uplink (UL) or downlink (DL) directions of BSs allocated inside urban-dense and urban CAs are performed using relation

$$
d_{\text {Murb } / d}=10 \frac{P_{T k}-P_{R t h}-\left[A+B \log _{10} f-13,82 \log _{10} h_{B S}-a\left(h_{U T}\right)\right]-S M F}{\left(44,9-6,55 \log _{10} h_{B S}\right)}[\mathrm{km}],
$$

Table 1 Path loss model (Okumura-Hata, COST-231) parameters

\begin{tabular}{lll}
\hline Parameter & Index & Value \\
\hline Constant (1500-2000 MHz) & $A$ & $46.3 \mathrm{~dB}$ \\
(Okumura-Hata/COST-231 model) & $B$ & $33.9 \mathrm{~dB}$ \\
Operating frequency & $f$ & $2100 \mathrm{MHz}$ \\
UT antenna height & $h_{U T}$ & $1.5 \mathrm{~m}$ \\
BS antenna height & $h_{B S}$ & $30 \mathrm{~m}$ \\
Correction factor for MS antenna height & $a\left(h_{U T}\right)$ & $-9.2 \times 0^{-3} \mathrm{~dB}$ \\
Area type correction factor & $C_{m}$ & $0 \mathrm{~dB}$ \\
Slow fading margin (UL/DL calculation) & $S F M$ & $13.16 \mathrm{~dB}$ \\
Standard deviation/point location & $\sigma$ & $8 \mathrm{~dB} / 95 \%$ \\
probability & & \\
UT (TC) sensitivity threshold & $P_{\text {Rth }}$ & $-117 \mathrm{dBm}$ \\
BS (CS) sensitivity threshold & $P_{\text {Rth }}$ & $-121 \mathrm{dBm}$ \\
\hline
\end{tabular}

while the next relation has been used for calculating BSs coverage inside sub-urban CA

$$
\begin{aligned}
& d_{\text {Msurb }} \\
& \quad=10 \frac{{ }_{T \text { Tk }}-P_{\text {Rth }}-\left[A+B \log _{10} f-13,82 \log _{10} h_{B S}-a\left(h_{U T}\right)\right]+\left\{2\left[\log _{10}(f / 28)\right]^{2}+5,4\right\}-S M F}{\left(44,9-6,55 \log _{10} h_{B S}\right)}[\mathrm{km}] .
\end{aligned}
$$

Descriptions and numerical values of each parameter used in relations (1) and (2) can be found in Table 1 . In relations (1) and (2), the $P_{T k}$ stands for total Tx power radiated from BSS antenna. Selected parameter values are characteristic for UMTS networks and the COST 231
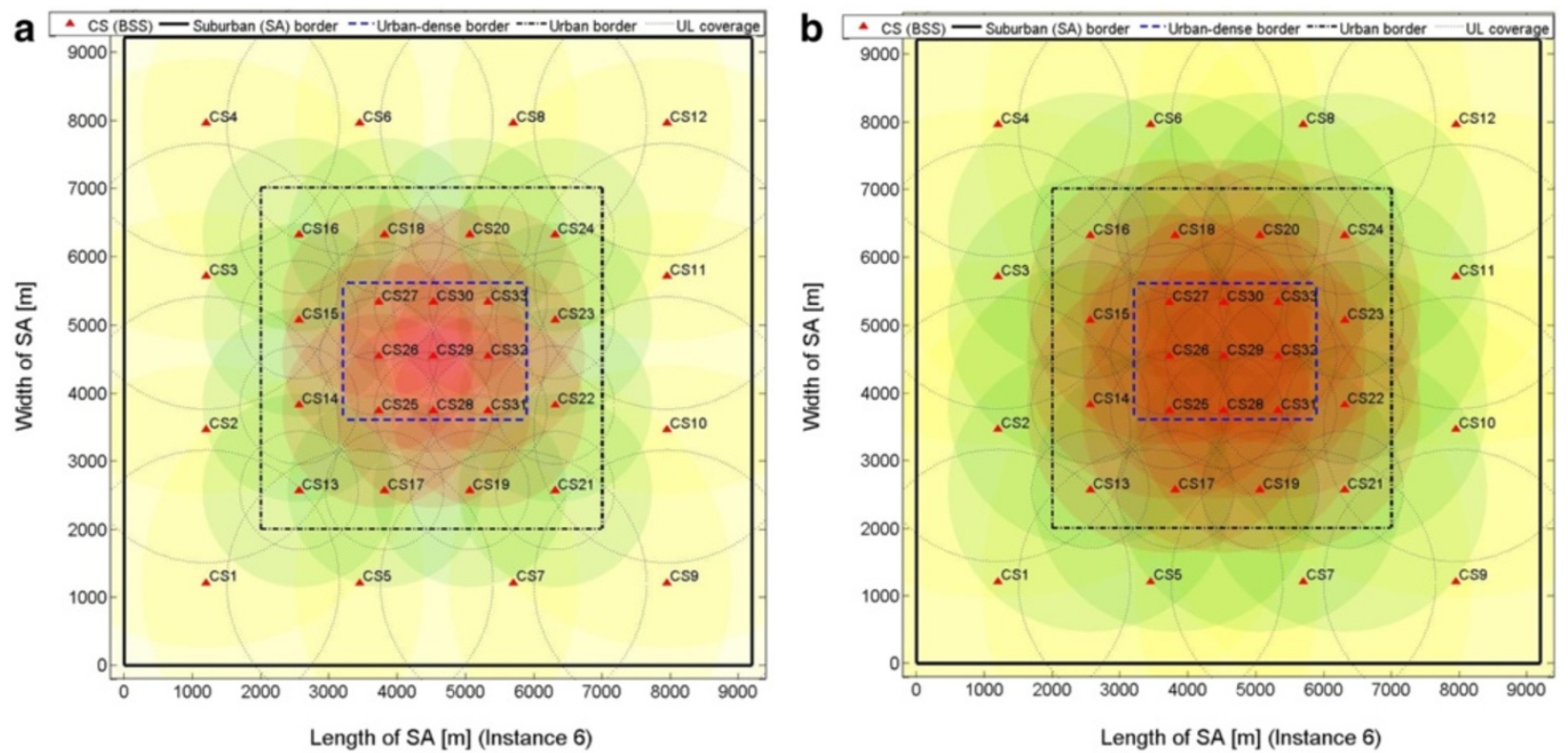

Figure 1 Guide borders among different propagation areas and DL CAs of each BSS transmitting at (a) 10 W, (b) 40 W. 
Table 2 Maximal coverage distances for different Tx powers

\begin{tabular}{lcl}
\hline Tx power $\boldsymbol{P}_{\boldsymbol{T} \boldsymbol{k}}$ & $\begin{array}{l}\text { Urban/urban dense } \\
\text { area }\left(\boldsymbol{d}_{\text {Murb/d }}\right)\end{array}$ & $\begin{array}{l}\text { Sub-urban area } \\
\left(\boldsymbol{d}_{\text {Msurb }}\right)\end{array}$ \\
\hline Downlink BS coverage & $($ COST-231 model) \\
$10 \mathrm{~W}(40 \mathrm{dBm})$ & $1.416 \mathrm{~km}$ & $3.193 \mathrm{~km}$ \\
$20 \mathrm{~W}(43 \mathrm{dBm})$ & $1.723 \mathrm{~km}$ & $3.885 \mathrm{~km}$ \\
$30 \mathrm{~W}(44.77 \mathrm{dBm})$ & $1.935 \mathrm{~km}$ & $4.361 \mathrm{~km}$ \\
$40 \mathrm{~W}(46 \mathrm{dBm})$ & $2.097 \mathrm{~km}$ & $4.727 \mathrm{~km}$ \\
Uplink UT coverage $(C O S T-231 \mathrm{model})$ & \\
Tx Power & Urban $/$ urban dense & Sub-urban area \\
& area $\left(d_{\text {Murb/d }}\right)$ & $\left(d_{\text {Msurb }}\right)$ \\
0.7 W $(28.4 \mathrm{dBm})$ & $0.864 \mathrm{~km}$ & $1.949 \mathrm{~km}$ \\
\hline
\end{tabular}

model [28-30]. Table 2 presents calculated values of maximal coverage distances in UL and DL directions from BS, for three different propagation environments. Selected values of the receiver sensitivity thresholds $P_{R t}$ equal to $-117 \mathrm{dBm}$ for user (mobile) terminal (UT) and $-121 \mathrm{dBm}$ for BS are in compliance with practical implementations and 3GPP standards [31,32]. Obtained BS and UT coverage distances are, from a practical point of view, typical for corresponding propagation environments of the real UMTS networks.

It is necessary to emphasize that coverage planning of analyzed UMTS networks has been made according to maximal coverage distances in the UL direction. This is because lower Tx power levels of UTs (up to $1 \mathrm{~W}$ ) results in lower maximal coverage distances if compared with the coverage distances of BSs which are much higher in DL due to higher Tx powers (Table 2). In the analyses, for simplicity a fixed Tx power level of UT equal to $0.7 \mathrm{~W}$ is assumed and such a Tx power is characteristic for most mobile phones nowadays. As presented in Table 2, we performed analyses for four BS Tx power levels and even for the lowest Tx power level (10 W), DL coverage of the BS sector is higher than the maximal coverage range of UT in the UL direction. This motivates us to select maximal coverage in the UL direction as asset for network coverage planning. Therefore, possible wireless links between the UT and BS can be accomplished only if the UT can reach the BS in the UL direction, which is also an attribute of real UMTS networks.

\section{Network model}

Research presented in this article is primarily focused on improving energy-efficiency of the UMTS terrestrial radio access network, and more specifically, the base transceiver stations (or BS) also known as Node B's. Hence, in this article, the BS will be a term describing the hardware and software of one UMTS Node B installed inside one cabinet. In addition, the BSS will refer to a physical location hosting installed cellular network equipment consisting of one or more BS cabinets, antenna lines, power supply and if it is necessary, site cooling system.

In order to analyze possible energy savings in the UMTS networks, we have developed network instances that are similar to those of real UMTS networks. Analyses have been performed on 12 different network instances and Figure 2a,b shows the structure of the two arbitrarily selected UMTS network instances. We assume two different types of network: the first one with all BSSs having omni-directional antennas-also called one-sector (cell) BSSs. In addition, we analyze the second network type consisting of only the three-sector (cell) BSSs. Regarding the one-sector BSSs, we assume omnidirectional antenna with $360^{\circ}$ horizontal radiation pattern around the BSS, while in the case of the three-sector BSSs, the assumption is that each sector covers $120^{\circ}$ of horizontal area.

Hence, the first six analyzed network instances (indicated as Instances 1-6) have consisted of one-sector BSSs (e.g., Instance 2 in Figure 2a). The other six instances indicated as Instances 7-12 contain three-sector BSSs (e.g., Instance 10 in Figure 2b). Although most UMTS network architecture nowadays combine single and multisector BSSs, we have decided to investigate these two different network types separately, due to expected differences in energy savings potential. For each of the analyzed instances, we performed a random allocation of 33 macro BSSs inside a $9.2 \times 9.2 \mathrm{~km}^{2}$ SA (Figure 2a,b). Such a square SA size equal to approximately $85 \mathrm{~km}^{2}$ corresponds to a broader area of a medium sized city. From a practical point of view, it is reasonable to believe that the allocated number of BSSs inside an SA of that size fairly corresponds to a number of BSSs that will be allocated by a single operator in the real coverage planning case.

Furthermore, inside the SA of each network instance we have allocated a different number of user terminals (UTs) representing users demanding a specific type of network service (Figure 2a,b). Modeling of each user as an individual UT in the UMTS network can significantly increase the computational complexity of the optimization model. In order to keep computational complexity on an acceptable level whilst ensuring precise information about number and user positions in the network, representations of UTs have been performed through the introduction of traffic clusters (TCs). The TC is envisioned as the cluster (group) comprised of one or more UTs allocated at a close proximity to each other (Figure 2). In addition, we have decided to use two types of TCs denoted as

- TC1 - representing a group of five UTs (users) always demanding voice (speech) service, and 

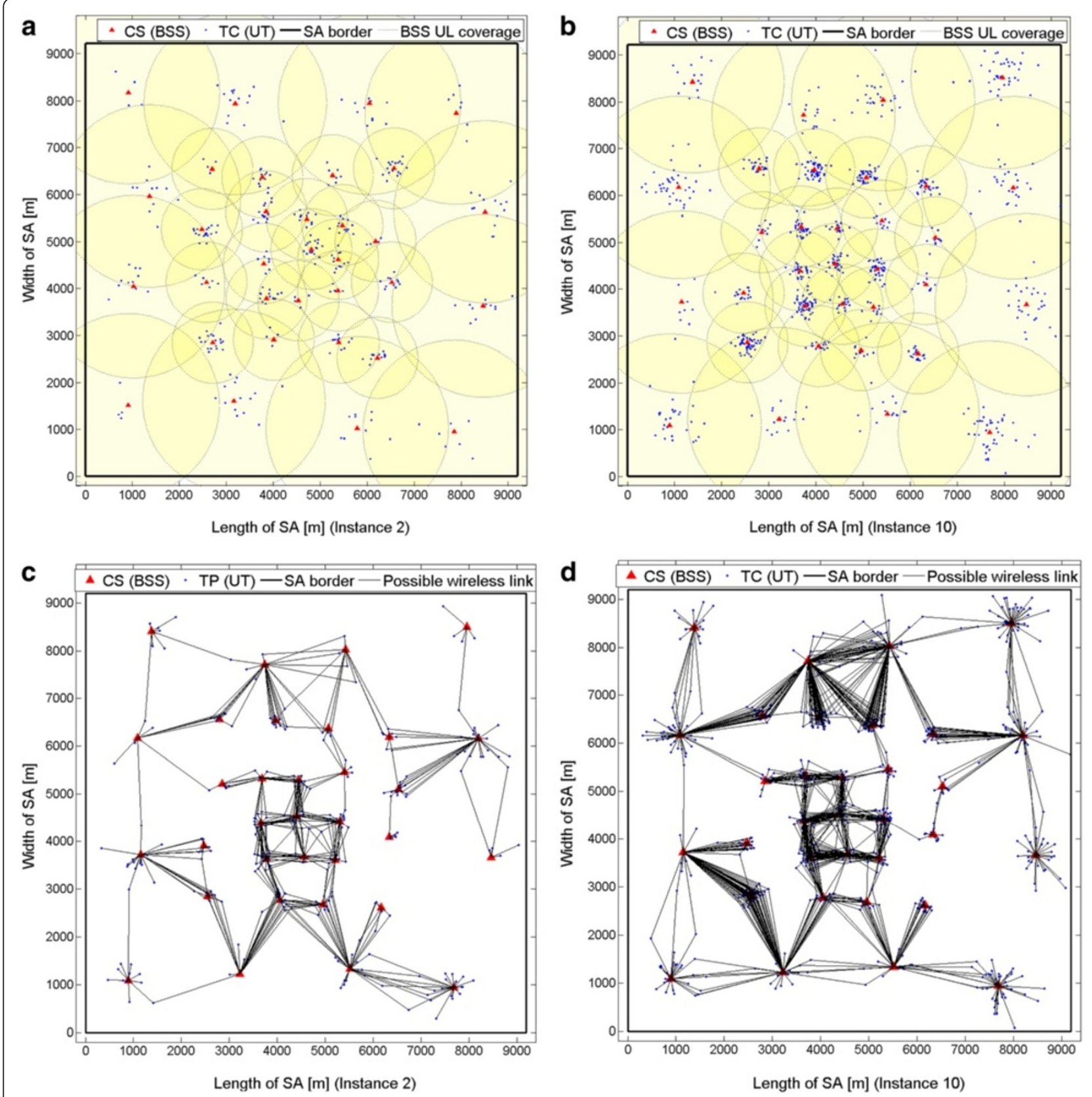

Figure 2 Allocation of CSs (BSSs) and TPs (UTs) inside SA for (a) one-sector BSSs (Instance 2), (b) three-sector BSSs (Instance 10), Visualization of potential wireless links among CSs (BSSs) and TPs (UTs) for (c) one-sector BSSs (Instance 2), (d) three-sector BSSs (Instance 10).

- TC2-representing one data UT (user) always demanding a corresponding type of service.

For simplicity, we use in the analyses only two different types of service (voice and data) simultaneously offered to users allocated inside SA of the analyzed UMTS instances. Although in the real-life situations a user with an advance mobile device like a smart phone can in one moment demand voice and in another moment data service, we assume for simplicity that voice users always demand voice service while data users request only data service. Table 3 gives precise information about the allocated TCs and corresponding number of voice and data users for each of the analyzed UMTS network instances. Allocation of the TCs performed randomly inside CAs of BSSs have been illustrated in Figure 2a for the network with one-sector BSSs (Instance 2) and in Figure $2 \mathrm{~b}$ for the network having three-sector BSSs 
Table 3 Statistics of allocated voice and data TCs inside SA for each of analyzed instances

\begin{tabular}{|c|c|c|c|c|c|c|c|c|c|c|}
\hline \multirow{2}{*}{$\begin{array}{l}\text { Types of traffic } \\
\text { centroids (TCs) }\end{array}$} & \multirow{2}{*}{$\begin{array}{l}\text { Number of voice } \\
\text { users in TC }\end{array}$} & \multirow{2}{*}{$\begin{array}{l}\text { Number of data } \\
\text { users in TC }\end{array}$} & \multirow{2}{*}{$\begin{array}{l}\text { Total number of } \\
\text { users in each TC }\end{array}$} & \multirow{2}{*}{$\begin{array}{l}\text { Guaranteed bit rates } \\
\text { for data/voice users } \\
\text { in TC1/TC2 (kb/s) }\end{array}$} & \multicolumn{6}{|c|}{ Instance number } \\
\hline & & & & & $\begin{array}{c}1 / 7 \\
(1 \text { s BSS/ } \\
3 \text { s BSS) }\end{array}$ & $\begin{array}{c}2 / 8 \\
(1 \text { s BSS/ } \\
3 \text { s BSS) }\end{array}$ & $\begin{array}{c}3 / 9 \\
(1 \text { s BSS/ } \\
3 \text { s BSS) }\end{array}$ & $\begin{array}{c}4 / 10 \\
(1 \text { s BSS/ } \\
3 \text { s BSS) }\end{array}$ & $\begin{array}{c}5 / 11 \\
(1 \text { s BSS/ } \\
3 \text { s BSS })\end{array}$ & $\begin{array}{c}6 / 12 \\
(1 \text { s BSS/ } \\
3 \text { s BSS) }\end{array}$ \\
\hline $\begin{array}{l}\text { TC1 (type 1) } \\
\text { TC2 (type 2) }\end{array}$ & $\begin{array}{l}0 \\
5\end{array}$ & $\begin{array}{l}1 \\
0\end{array}$ & $\begin{array}{l}1 \\
5\end{array}$ & $\begin{array}{l}384 / 128 / 64 \\
12.2\end{array}$ & & & & & & \\
\hline \multicolumn{5}{|c|}{ Total number of TCs inside SA (one-sector BSS) } & 389 & 343 & 359 & 287 & 391 & 379 \\
\hline \multicolumn{5}{|c|}{ Total number of voice users inside SA (one-sector BSS) } & 1660 & 1365 & 1470 & 1005 & 1680 & 1600 \\
\hline \multicolumn{5}{|c|}{ Total number of data users inside SA (one-sector BSS) } & 57 & 70 & 65 & 86 & 55 & 59 \\
\hline \multicolumn{5}{|c|}{ Total number of TCs inside SA (three-sector BSS) } & 1092 & 907 & 849 & 796 & 945 & 1109 \\
\hline \multicolumn{5}{|c|}{ Total number of voice users inside SA (three-sector BSS) } & 4725 & 3570 & 3210 & 2880 & 3810 & 4830 \\
\hline \multicolumn{5}{|c|}{ Total number of data users inside SA 3 (three-sector BSS) } & 147 & 193 & 207 & 220 & 183 & 143 \\
\hline \multicolumn{5}{|c|}{ Total number of CSs (BSSs) representing 1or 3 sector BSS } & 33 & 33 & 33 & 33 & 33 & 33 \\
\hline \multicolumn{5}{|c|}{ SA size $\left(\mathrm{km}^{2}\right) / \mathrm{SA}$ dimensions } & \multicolumn{6}{|c|}{$84.64 \mathrm{~km}^{2} / 9.2 \times 9.2 \mathrm{~km}$} \\
\hline \multicolumn{5}{|c|}{ Number of MPs/MP density $(m \times m)$} & \multicolumn{6}{|c|}{$17,161 / 70 \times 70 \mathrm{~m}$} \\
\hline
\end{tabular}


(Instance 10). It can be noticed that the allocation densities of TCs have been higher around locations of the BSSs. This is related to the selection of BSS locations, which, in the real networks, are performed such that they are always placed on traffic hot spots. As such they offer the best power budget for the mobile users served by those BSSs. Therefore, with this allocation approach, we want the analyzed instances to be as close as possible to the real UMTS networks.

For the same network instances visualized in Figure 2a, b, potential wireless links between BSSs and TCs can be seen for instances with one-sector BSSs in Figure 2c and for instances with three-sector BSSs in Figure 2d. Potential wireless links can be obtained only if the coverage criteria explained in previous section has been satisfied. Therefore, potential wireless links indicate on which BS(s) each of TCs (UTs) can be connected. In Figure 3a, $\mathrm{b}$, it can be perceived that TCs located inside urban-dense CAs have higher possibilities in terms of potential connections with BSs if compared with TCs located within sub-urban CAs. This is fully in compliance with practical coverage situations of real UMTS networks.

According to Table 4, we assume that an active BS dynamically changes $\mathrm{Tx}$ power among four discrete power levels $(10,20,30$, and $40 \mathrm{~W})$ denoted with index $k$ in Table 4. Based on 3rd Generation Partnership Project (3GPP) standards [32], we analyzed macro BSs belong to the category of wide area BSs. In general, instantaneous BSS power consumption can be divided into two components: fixed $\left(P_{j}\right)$ and variable $\left(P_{k}\right)$. Fixed power consumption $P_{j}(\mathrm{~W})$ is constant in time and is dedicated to signal processing, analog/digital (A/D) conversion, battery supply, etc. Power amplifier and site cooling are the two most significant contributors to the variable power consumption $P_{k}(\mathrm{~W})$ which increases with enlargement of the Tx power. Therefore, the total instantaneous power consumption of a BSS in any moment can be expressed as a summation of these two components

$$
P_{t o t}=P_{j}+P_{k} \quad[\mathrm{~W}] .
$$

Total power consumptions for one- and three-sector BSSs transmitting at different Tx power levels are presented in Table 4. Assuming one frequency carrier per BSS sector, instantaneous BSS power consumptions for each of the four Tx power levels have been presented in Table 4.

\subsection{Traffic approximation}

In order to model the influence on network energy consumption of the BS switching granularity, we performed an approximation of the real traffic pattern obtained for the cellular access networks through on-site measurements [33]. Approximation is based on discretization of the real traffic pattern $f_{R}(t)$ using three distinct approximation approaches. The first approach assumes equal traffic patterns for working and weekend days. According to Figure $3 \mathrm{a}$, the discretization function $f_{A 7}(t)$ is based on seven discrete time periods during 1 day. The second approximation approach is also based on the same number of discrete time periods (seven), but it takes into account differences among traffic profiles of the working and weekend days (Figure 3a,b). The third approximation, also presented in Figure $3 \mathrm{a}$, assumes finer-grained discretization with 24 time periods $\left(f_{A 24}\right)$ in the case of a working day only. Table 5 lists for each approximation the beginning and ending times of each time period with the time duration of each time period and percentages of active users. Using such approximation approaches, besides the impact of switching granularity, we can also perceive the influence of different working-
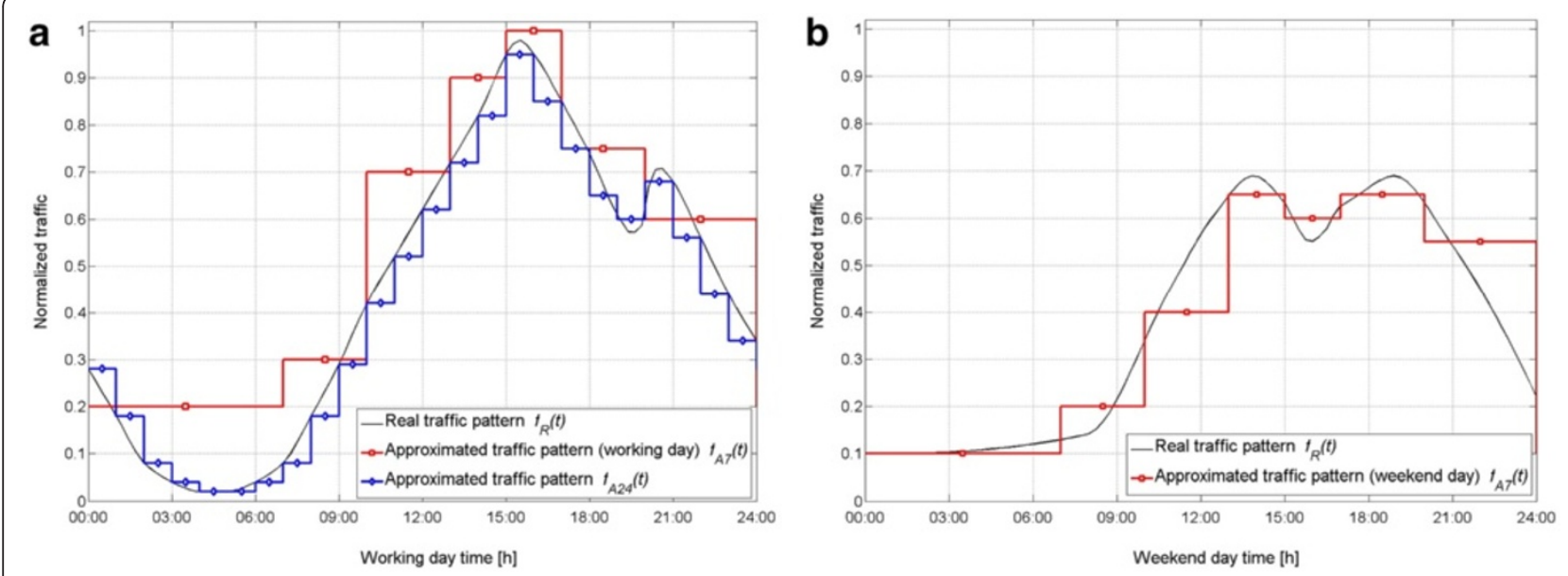

Figure 3 Approximation of the real traffic pattern for (a) working day using seven $\left(f_{A 7}\right)$ and $24\left(f_{A 24}\right)$ time periods, (b) weekend day using seven $\left(f_{A 7}\right)$ time periods. 
Table 4 Instantaneous BSS power consumption (one-carrier/sector)

\begin{tabular}{|c|c|c|c|c|c|}
\hline \multicolumn{2}{|c|}{ Tx powers } & \multirow{2}{*}{$\begin{array}{l}1 \mathrm{~s} \text { BSS fixed } \\
\left(P_{j}\right) / \text { variable }\left(P_{k}\right) \text { power } \\
\text { consumption (W) }\end{array}$} & \multirow{2}{*}{$\begin{array}{l}3 \mathrm{~s} \mathrm{BSS} P_{\text {tot }} \text {-total } \\
\text { instantaneous power } \\
\text { consumption (W) }\end{array}$} & \multirow{2}{*}{$\begin{array}{l}1 \mathrm{~s} \text { BSS fixed } \\
\left(P_{j}\right) / \text { variable }\left(P_{k}\right) \text { power } \\
\text { consumption }(\mathrm{W})\end{array}$} & \multirow{2}{*}{$\begin{array}{l}3 \mathrm{~s} \mathrm{BSS} P_{\text {tot }}-\text { total } \\
\text { instantaneous power } \\
\text { consumption (W) }\end{array}$} \\
\hline $\begin{array}{l}\text { Tx power } \\
\text { level } k\end{array}$ & $\begin{array}{l}\text { Tx power } \\
P_{T k}(\mathrm{~W} / \mathrm{dBm}) \\
\end{array}$ & & & & \\
\hline 4 & $10 / 40$ & $330 / 66.66$ & 396.66 & $819 / 259.97$ & $1,087.97$ \\
\hline 3 & $20 / 43$ & $330 / 133.33$ & 463.33 & $819 / 519.9$ & $1,338.9$ \\
\hline 2 & $30 / 44.77$ & $330 / 200$ & 530 & $819 / 780$ & 1,599 \\
\hline 1 & $40 / 46$ & $330 / 266.66$ & 596.66 & $819 / 1039$ & 1,858 \\
\hline
\end{tabular}

day and weekend-day traffic profiles on network power consumption.

\section{Capacity planning}

In order to make a realistic estimation of the number of users that can potentially be served by the UMTS network, complete network capacity planning including capacity planning of each BSS needs to be performed. To do this, distribution of traffic to the different voice and data calls inside each BSS CA should be known as accurately as possible. Hence, in the dimensioning phase, a fixed load for all BSSs within the SA is assumed. The value for the load can be the maximum acceptable load (MAL) per sector (cell) or it can be the predicted load (PL) per sector during the busy hour. Both of these loads will be used in this article for estimation purposes.

The MAL is maximal load that can be accepted by BSS sector(s) according to the technological hardware and software capabilities of BSS. Values of MAL define the maximal number of TCs (voice and data users) that can simultaneously be served by each BSS while transmitting at some Tx power level. Actually, the idea is to use the complete BSS capacity contained within the MAL when a BSS needs to take over the load of those BSSs that go to off state due to energy-efficient resource management. On the other hand, we use the term PL to express a realistic number of TCs that will be allocated for simulation purposes inside the CA of a BSS during busy hours. Hence, the PL is the highest load served by BSS which periodically occurs each day during busy hour. Values of the PL define maximal number of TCs which will be allocated inside each BSS CA of analyzed network instances. The PL is always lower than the MAL and in practice ranges between 70 and $90 \%$ of the MAL. Therefore, in the performed capacity planning we consider a value of average PL $\bar{\eta}$ equal to $80 \%$.

WCDMA capacity planning is directly related to the power budget (Tx power) and thus to the BSS CA. For that reason, coverage and capacity planning have been made together in this article. Two approaches in the capacity planning known as uplink (UL) or downlink (DL) capacity planning can be used for estimating the number of users simultaneously served by UMTS BSS.
Since the DL load is generally higher than the UL load, our capacity planning for analyzed networks has been done based on DL capacity estimation. In the DL, there are two aspects that should be considered. First, the interference from other cells $\bar{\imath}$, and, the Tx power $P_{T k}$ of the BS. Computation of the theoretical WCDMA load is straightforward in the DL and is based on the so-called capacity load (pole) equations. For the calculation of an average BS load $\bar{\eta}$ in the DL direction we use the following equation $[30,34]$

$$
\bar{\eta}=\sum_{z=1}^{q} \sum_{i=1}^{n} \frac{\left(E_{b} / N_{o}\right)_{z, i} v_{z, i}}{W / R_{z, i}}[(1-\bar{\alpha})+\bar{\imath}]
$$

where index $q$ defines maximal number of different services offered to the users, and $n$ corresponds to the maximal number of simultaneously served users of $z$ th service. In addition, meanings of each parameter used in relation (4) and corresponding numerical values can be found in Table 6. The selected values are typical for UMTS networks and references for the selected values can be found in $[30,34]$. Recoiling previous assumptions, we envisioned two different types of service $(q=2)$; voice (TC1) and data (TC2). Although UMTS systems use adaptive multirate speech coder [27], which is actually several coders in one providing dynamic changes of different speech coding rates during a call, for simplicity we performed analyses assuming that UMTS network always ensures fixed rates of $12.2 \mathrm{~kb} / \mathrm{s}$ for voice service. In addition, we performed analyses assuming that UMTS network guarantees inside a complete SA one of three fixed data rates equal to: 384,128 , and $64 \mathrm{~kb} / \mathrm{s}$. These voice/data rates are ensured in each part of the BSS CA and they are typical for modern UMTS networks deployed worldwide. Although a network adopts the data rates of each individual user according to the quality of the radiopropagation link, we neglect this fact since one of our goals is to determine the influence of a guaranteed service rate on network energy consumption. Therefore, we perform analyses assuming that in any moment, the network simultaneously offers to the voice users a rate of $12.2 \mathrm{~kb} / \mathrm{s}$ for ensuring voice service, and only one of the three data rates for guaranteeing data service to the data 
Table 5 Different approaches in approximations of the real traffic pattern

\begin{tabular}{|c|c|c|c|c|c|c|c|c|c|c|c|}
\hline \multicolumn{6}{|c|}{ Traffic approximation with 7 time periods } & \multicolumn{6}{|c|}{ Traffic approximation with 24 time periods } \\
\hline $\begin{array}{l}\text { Time } \\
\text { period } t \\
\text { for } f_{A 7}(t)\end{array}$ & $T_{t}(\mathrm{~h})$ & $T_{t+1}(\mathrm{~h})$ & $\Delta T_{t}=T_{t+1}-T_{t}(\mathrm{~h})$ & $\begin{array}{l}\% \text { of active } \\
\text { users (TCs) } \\
\text { working day }\end{array}$ & $\begin{array}{l}\% \text { of active } \\
\text { users (TCs) } \\
\text { weekend day }\end{array}$ & $\begin{array}{l}\text { Time period } \\
t(h h-h h) \\
\text { for } f_{A 24}(t)\end{array}$ & $\begin{array}{l}\% \text { of active } \\
\text { users }(\mathrm{TCs}) \\
f_{A 24}(t)\end{array}$ & $\begin{array}{l}\text { Time period } \\
t(h h-h h) \\
\text { for } f_{A 24}(t)\end{array}$ & $\begin{array}{l}\% \text { of active } \\
\text { users (TCs) }\end{array}$ & $\begin{array}{l}\text { Time period } \\
t(h h-h h) \text { for } \\
f_{A 24}(t)\end{array}$ & $\begin{array}{l}\% \text { of active } \\
\text { users (TCs) }\end{array}$ \\
\hline $1(8)$ & 00 & 07 & 7 & 20 & 10 & $1(00-01)$ & 28 & $9(08-09)$ & 18 & $17(16-17)$ & 85 \\
\hline $2(9)$ & 07 & 10 & 3 & 30 & 20 & $2(01-02)$ & 18 & $10(09-10)$ & 29 & $18(17-18)$ & 75 \\
\hline $3(10)$ & 10 & 13 & 3 & 70 & 40 & $3(02-03)$ & 8 & $11(10-11)$ & 42 & $19(18-19)$ & 65 \\
\hline $4(11)$ & 13 & 15 & 2 & 90 & 65 & $4(03-04)$ & 4 & $12(11-12)$ & 52 & $20(19-20)$ & 60 \\
\hline $5(12)$ & 15 & 17 & 2 & 100 & 60 & $5(04-05)$ & 2 & $13(12-13)$ & 62 & $21(20-21)$ & 68 \\
\hline $6(13)$ & 17 & 20 & 3 & 75 & 65 & $6(05-06)$ & 2 & $14(13-14)$ & 72 & $22(21-22)$ & 56 \\
\hline 7 (14) & 20 & 24 & 4 & 60 & 55 & $7(06-07)$ & 4 & $15(14-15)$ & 82 & $23(22-23)$ & 44 \\
\hline / & / & / & / & I & / & $8(07-08)$ & 8 & $16(15-16)$ & 95 & $24(23-00)$ & 34 \\
\hline
\end{tabular}


Table 6 Parameters used for capacity estimation of BSS

\begin{tabular}{|c|c|c|}
\hline Parameter description & Index & Value \\
\hline $\begin{array}{l}\text { Mean other-to-own cell } \\
\text { interference factor }\end{array}$ & $\bar{\imath}$ & $\begin{array}{l}0.55(1 \mathrm{~s} \text { BSS }) / 0.65 \\
(3 \mathrm{~s} \text { BSS) }\end{array}$ \\
\hline $\begin{array}{l}\text { Maximal number of different } \\
\text { services in the cell }\end{array}$ & 9 & 2 \\
\hline System chip rate (bandwidth) & W & 3,840,000.00 chips/s \\
\hline \multirow{4}{*}{$\begin{array}{l}\text { Bit energy per noise spectral } \\
\text { density (interference) ratio }\end{array}$} & \multirow[t]{4}{*}{$E_{b} / N_{o}$} & $6.5 \mathrm{~dB}(12.2 \mathrm{~kb} / \mathrm{s})$ \\
\hline & & $5.5 \mathrm{~dB}(64 \mathrm{~kb} / \mathrm{s})$ \\
\hline & & $5 \mathrm{~dB}(128 \mathrm{~kb} / \mathrm{s})$ \\
\hline & & $4.5 \mathrm{~dB}(386 \mathrm{~kb} / \mathrm{s})$ \\
\hline $\begin{array}{l}\text { Bit rate of user } i \text { demanding } z \text { th } \\
\text { type of service }\end{array}$ & $R_{z, i}$ & $12.2 / 64 / 128 / 384 \mathrm{~kb} / \mathrm{s}$ \\
\hline $\begin{array}{l}\text { Activity factor in DL for ith TC } \\
\text { demanding zth type of service }\end{array}$ & $V_{z, i}$ & 0.58 (voice)/0.7 (data) \\
\hline Mean orthogonality factor & $\bar{a}$ & 0.5 \\
\hline $\begin{array}{l}\text { Noise spectral density of the } \\
\text { receiver front end }\end{array}$ & $N_{r f}$ & $-167 \mathrm{~dB}$ \\
\hline Mean path loss margin & & $10 \mathrm{~dB}$ \\
\hline Path loss at cell border & & $149.4 \mathrm{~dB}$ \\
\hline $\begin{array}{l}\text { Mean path loss between BS } \\
\text { and UT }\end{array}$ & $\bar{L}$ & $139.4 \mathrm{~dB}$ \\
\hline DL mean cell (sector) load (PL) & $\bar{\eta}$ & $80 \%$ \\
\hline
\end{tabular}

users. From relation (4), interdependence between number of voice $\left(n_{V}\right)$ and data $\left(n_{D}\right)$ users that can simultaneously be served by a single BSS can be expressed as

$$
n_{D}=\frac{\bar{\eta} W-[(1-\bar{\alpha})+\bar{\iota}] n_{V}\left(E_{b} / N_{o}\right)_{V} R_{V} v_{V}}{[(1-\bar{\alpha})+\bar{\iota}]\left(E_{b} / N_{o}\right)_{D} R_{D} v_{D}} .
$$

Because the output Tx power $\left(P_{T k}\right)$ of the BS transmitter is detected among all users inside a sector, it is possible that the power of the transmitter(s) limits the capacity in the DL direction. The required BS Tx power $\left(P_{T k}\right)$ for the case of a single service type is given in the following equation $[27,31]$

$$
P_{T k}=\frac{N_{r f} W \bar{L} \sum_{i=1}^{n} \frac{\left(E_{b} / N_{o}\right)_{i} v_{i}}{W / R_{i}}}{1-\sum_{i=1}^{n} \frac{\left(E_{b} / N_{o}\right)_{i} v_{i}}{W / R_{i}}[(1-\bar{\alpha})+\bar{\imath}]} \quad[\mathrm{dBm}]
$$

Values of newly introduced parameters such as noise spectral density $N_{r f}$ of the receiver front end and the average path loss between BS and user (mobile) terminal $\bar{L}$ can be found in Table 6 . Without loss of generality, we assume that the feeder and combiner losses have been compensated with the antenna gain, and therefore an effective isotropic radiated power of $\mathrm{BS}$, denoted as $\mathrm{Tx}$ power $P_{T k}$, is equal to the power at the output of a power amplifier.

According to relation (5), it is possible to develop an equation which defines the maximal number of users (MAL) that can be served in the cell for different Tx powers of BS as

$$
n_{D(V)}=\frac{0.85 \times P_{T k}}{\left(E_{b} / N_{o}\right)_{i} v_{i} R_{i}\left\{\frac{0.85 \times P_{T k}}{W}[(1-\bar{\alpha})+\bar{\imath}]+N_{r f} \bar{L}\right\}} .
$$

In relation (7), the total BS Tx power $P_{T k}$ is scaled with a value equal to 0.85 , since $15 \%$ of the total Tx power of $\mathrm{BS}$ goes to the WCDMA control channels. Using relations (5) and (7), we manage to perform capacity planning of the analyzed UMTS networks. The capacity estimations in terms of maximal number of voice and data users (MAL) which can independently be served by single BS sector at different Tx powers have been presented in Figure 4a,b, respectively. Estimations have been performed according to the relation (7) for the case of different other-to-own cell interference factors that are characteristic for one (omni-directional) sector $(\bar{l}=0.55)$ and three-sector $(\bar{l}=0.65)$ sites $[30,34]$. Obviously, for the site capacitating concept it can be said that the higher the Tx power, the higher the number of voice or data users that can be (separately) served by BSS.

Based on the estimations presented in Figures 4a,b, we can calculate the maximal number of voice and data TCs which can independently be served by a BSS while transmitting at one of the Tx power levels $k$. Capacities have been presented for one-sector and three-sector BSSs in Table 7. These maximal BSS capacities $c_{k z}$ are calculated for the cases of guaranteed voice/data rate combinations equal to $12.2 / 384,12.2 / 128$, and $12.2 / 64 \mathrm{~kb} / \mathrm{s}$. Table 7 indicates that guaranteeing service of lower data rates results in higher number of data TCs (TC2) which can simultaneously be served by a single BSS for the same Tx power levels. Although BSS capacity significantly depends on many factors such as interference (which is the most dominant), obtained capacity values are typical for most one (omni-directional) and three-sector BSSs nowadays.

In addition, assuming $80 \%$ of the PL for a single BSS sector, Figure 4c,d presents interdependence between the number of voice and data users that can simultaneously be served by single sector $(\bar{l}=0.55)$ and three-sector $(\bar{l}=0.65)$ BSSs, respectively. Figure 4 indicates that with an increase in the number of served data users, the number of simultaneously served voice users decreases, and vice versa. Also, extreme points on the abscissas and ordinates of the graphs in Figure 4c,d present two adversary cases indicating the maximal number of voice and 

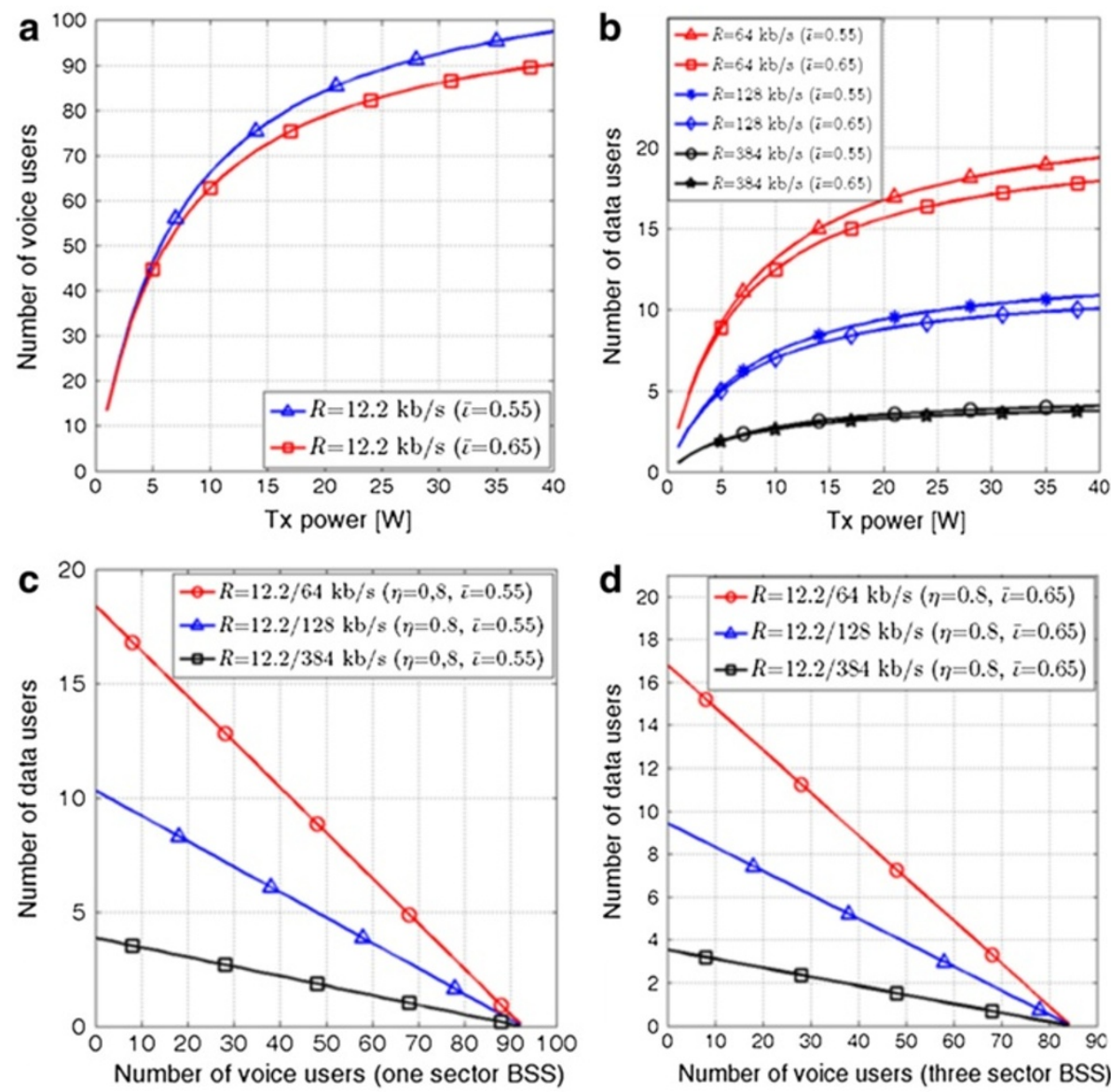

Figure 4 Estimated capacity of 3G BS for different Tx powers in terms of (a) maximal number of voice users, (b) maximal number of data users, estimated interdependence of simultaneously connected voice and data users for case of (c) one-sector 3G BSS, (d) threesector 3G BSS.

data users that can be served independently by BS for a PL equal to $80 \%(\bar{\eta}=0.8)$.

\section{Optimization model}

In order to mathematically formulate the problem of energy-consumption optimization of a whole UMTS network, we use ILP methods. More specifically, we develop an optimization model that is based on BIP, assuming that the network scales energy consumption in accordance with quantity of guaranteed rates for data (voice) service and daily variations in number of active users. Scaling of energy consumption is based on the possibility to completely turn off some of the BSSs in situations when the number of active users inside the CA of those

Table 7 Estimated maximal number of voice and data TCs that can independently be served by single BSS for different service rates

\begin{tabular}{|c|c|c|c|c|c|c|c|c|c|c|c|c|c|}
\hline \multirow[t]{2}{*}{$\begin{array}{l}\text { Level of } \\
\text { sector Tx } \\
\text { power } \\
k\end{array}$} & \multirow{2}{*}{$\begin{array}{l}\text { Sector Tx } \\
\text { power }\end{array}$} & \multicolumn{2}{|c|}{$\begin{array}{l}\text { One-sector } \\
\text { BSS capacity } c_{k z} \\
\text { service rates: } \\
\text { voice/data } \\
12.2 / 384 \mathrm{~kb} / \mathrm{s}\end{array}$} & \multicolumn{2}{|c|}{$\begin{array}{l}\text { Three-sector BSS } \\
\text { capacity } c_{k z} \\
\text { service rates: } \\
\text { voice/data } \\
12.2 / 384 \mathrm{~kb} / \mathrm{s}\end{array}$} & \multicolumn{2}{|c|}{$\begin{array}{l}\text { One-sector BSS } \\
\text { capacity } c_{k z} \\
\text { service rates: } \\
\text { voice/data } \\
12.2 / 128 \mathrm{~kb} / \mathrm{s}\end{array}$} & \multicolumn{2}{|c|}{$\begin{array}{l}\text { Three-sector } \\
\text { BSS capacity } c_{k z} \\
\text { service rates: } \\
\text { voice/data } \\
12.2 / 128 \mathrm{~kb} / \mathrm{s}\end{array}$} & \multicolumn{2}{|c|}{$\begin{array}{l}\text { One-sector } \\
\text { BSS capacity } c_{k z} \\
\text { service rates: } \\
\text { voice } / \text { data } \\
12.2 / 64 \mathrm{~kb} / \mathrm{s}\end{array}$} & \multicolumn{2}{|c|}{$\begin{array}{l}\text { Three-sector } \\
\text { BSS capacity } c_{k z} \\
\text { service rates: } \\
\text { voice/data } \\
12.2 / 64 \mathrm{~kb} / \mathrm{s}\end{array}$} \\
\hline & & $\begin{array}{l}\text { TC2 } \\
\text { number }\end{array}$ & $\begin{array}{l}\text { TC1 } \\
\text { number }\end{array}$ & $\begin{array}{l}\text { TC2 } \\
\text { number }\end{array}$ & $\begin{array}{l}\text { TC1 } \\
\text { number }\end{array}$ & $\begin{array}{l}\text { TC2 } \\
\text { number }\end{array}$ & $\begin{array}{l}\text { TC1 } \\
\text { number }\end{array}$ & $\begin{array}{l}\text { TC2 } \\
\text { number }\end{array}$ & $\begin{array}{l}\text { TC1 } \\
\text { number }\end{array}$ & $\begin{array}{l}\text { TC2 } \\
\text { number }\end{array}$ & $\begin{array}{l}\text { TC1 } \\
\text { number }\end{array}$ & $\begin{array}{l}\text { TC2 } \\
\text { number }\end{array}$ & $\begin{array}{l}\text { TC1 } \\
\text { number }\end{array}$ \\
\hline 1 & 40 & 4 & 20 & 12 & 54 & 11 & 20 & 30 & 54 & 19 & 20 & 54 & 54 \\
\hline 2 & 30 & 3 & 19 & 9 & 51 & 10 & 19 & 27 & 51 & 18 & 19 & 51 & 51 \\
\hline 3 & 20 & 3 & 17 & 9 & 48 & 9 & 17 & 24 & 48 & 17 & 17 & 48 & 48 \\
\hline 4 & 10 & 2 & 13 & 6 & 36 & 8 & 13 & 21 & 36 & 14 & 13 & 39 & 36 \\
\hline
\end{tabular}


BSSs becomes low. In addition, to accommodate guaranteed service rates for a diverse number of voice and data TCs, each BSS can dynamically adopt a Tx power by choosing from the set of Tx power levels denoted as $k \in K$ (Table 4). Since dynamic adaptation of Tx power has a direct influence on instantaneous BSS power consumption, such an approach contributes to reductions of network energy consumption.

Mathematical formulation of the optimization problem is based on a straightforward approach typical for radio coverage problems. Using such an approach, we define with $j \in J$ a set of CSs hosting BSS equipment and with $i \in I$ a set of TCs where each UT is located. We model the affinity between TCs and CSs (Figure 2c,d) by means of a bipartite and undirected graph $G(I, J)$. Let $G(I, J)$ be a graph with vertex set $V=\{I \mathrm{U}\}$ and such that there is an edge between $i \in I$ and $j \in J$ if and only if TC $i$ can reach BSS $j$ in the UL direction. Since each CS $j$ can ensure the transport of voice and data traffic, we define with $\mathrm{z} \in \mathrm{Z}$ a set of network services simultaneously offered to TCs. Each of the network services is delivered to the TCs during a set of time periods $t \in H$ (Table 5), and the time difference between consecutive time periods is denoted as $T_{t+1}-T_{t}$. Annotation of all sets, subsets, and indices used in the mathematical model has been listed in Table 8 .

To model the capacity of a BSS for a specific type of service $z$ when the BSS transmits at $k$ th Tx power, we introduce the parameter $c_{k z}$ (Table 7). According to Table 7 , the capacity parameter $c_{k z}$ defines the maximal number of voice and data TCs that can simultaneously be served by a single three-sector or one-sector BSS, when transmitting at different $\mathrm{Tx}$ power levels $k$. As explained in the previous section, numerical values of the parameter $c_{k z}$ for different combinations of guaranteed voice/data service rates have been calculated according to relations (5) and (7). In addition to the capacity parameter $c_{k z}$, we use four binary parameters which are actually $0-1$ incidence matrices defined as

$$
\begin{aligned}
& a_{i j k t}= \begin{cases}1 & \text { if TC } i \text { is covered during time period } t \\
& \text { by CS } j \text { transmitting at } k-\text { th Tx power } \\
0 & \text { otherwise }\end{cases} \\
& v_{i z}= \begin{cases}1 & \text { if } T C \text { i belongs to } z-\text { th type of network } \\
0 & \text { service } \\
\text { otherwise }\end{cases} \\
& d_{i t}= \begin{cases}1 & \text { if TC } \mathrm{i} \text { is in active (on) state during } \\
0 & \text { time period } \mathrm{t}\end{cases} \\
& b_{s j k}= \begin{cases}\text { if } s-\text { th measurement point is covered } \\
1 & \text { by } j-\text { th CS transmitting at } \mathrm{k}-\text { th Tx } \\
\text { power level } & \\
0 & \text { otherwise }\end{cases}
\end{aligned}
$$

\begin{tabular}{|c|c|c|c|}
\hline Set description & $\begin{array}{l}\text { Set } \\
\text { index }\end{array}$ & Set structure & $\begin{array}{l}\text { Maximum } \\
\text { number of } \\
\text { set elements }\end{array}$ \\
\hline Set of all CSs: J & j & $j \in J=\{1, \ldots, m\}$ & $m$ \\
\hline Set of all test points (TCs): I & $i$ & $i \in l=\{1, \ldots, n\}$ & $n$ \\
\hline Set of all Tx power levels: $K$ & k & $k \in K=\{1, \ldots, l\}$ & 1 \\
\hline Set of all time periods: $H$ & $t$ & $t \in H=\{1, \ldots, p\}$ & $p$ \\
\hline Set of all service types (voice/data) offered to users & $z$ & $z \in Z=\{1, \ldots, q\}$ & 9 \\
\hline Set of all measurement points (MPs): $S$ & s & $s \in S=\{1, \ldots, u\}$ & u \\
\hline $\begin{array}{l}\text { Subsets of Tx power levels detected for }(i, j) \\
\text { combination: } K(i j)\end{array}$ & k & $k \in K=\left\{1, \ldots, l_{i, j}\right\}$ & $l_{i, j}$ \\
\hline Subsets of TCs covered with $(j, k)$ combination: I(jk) & i & $i \in l(j k)=\left\{1, \ldots, n_{j, k}\right\}$ & $n_{j, k}$ \\
\hline Subsets of TCs covered with $(j, k, r)$ combination: I (jkr) & i & $i \in l(j k r)=\left\{1, \ldots, n_{j, k, r}\right\}$ & $n_{j, k, r}$ \\
\hline Subset of CSs allocated at points of basic grid (BG): $J^{*}$ & j & $j \in J^{*}=\left\{1, \ldots, m_{B G}\right\}$ & $m_{B G}$ \\
\hline $\begin{array}{l}\text { Sets of CS-configuration pairs covering TC } i: J K(i) \\
\text { Indexing of } J K(i) \text { set members (pairs): } b(i)\end{array}$ & $j_{b} k_{b} h$ & $j_{b}, k_{b} \in J K(i)=\left\{\left(j_{1}, k_{1}\right), \ldots,\left(j_{B(i)}, k_{B(i)}\right)\right\} h \in b(i)=\{1, \ldots, B(i)\}$ & $j_{B(i)}, k_{B(i)} B(i)$ \\
\hline $\begin{array}{l}\text { Subsets of TCs covered with }(j, k) \text { combination in } \\
\text { time period t: } /(j k t)\end{array}$ & i & $i \in l(j k t)=\left\{1, \ldots, n_{j, k, t}\right\}$ & $n_{j, k, t}$ \\
\hline $\begin{array}{l}\text { Subsets of TCs covered with }(j, k, r) \text { combination } \\
\text { in time period t: I(jkrt) }\end{array}$ & i & $i \in l(j k r t)=\left\{1, \ldots, n_{j, k, r, t}\right\}$ & $n_{j, k, r, t}$ \\
\hline
\end{tabular}

Table 8 Annotation of sets and indexes used in mathematical model 
Binary parameter a $\alpha_{i j k t}$ defines affiliation of TC $i$ inside the CA of the $j$ th CS transmitting at the $k$ th Tx power during time period $t . v_{i z}$ is binary parameter which defines belonging of the $i$ th TC to the specific service type $z$, while $d_{i t}$ denotes activity state of the $i$ th TC during each time period $t$. If the $i$ th TC is active during time period $t$, we assume an active state of all voice (TC1) or data (TC2) users belonging to that TC. More precisely, it can be said that all users in an active TC demand corresponding capacity resources of the UMTS network.

Coverage parameter $b_{s j k}$ indicates the determination of the $s$ th measurement point (MP) inside the CA of the $j$ th $\mathrm{CS}$, in the case when the CS transmits at the $k$ th Tx power level. For ensuring full coverage of a complete SA during all time periods, we introduce in our work [14] the concept of MPs which is based on a set $s \in S$ (Table 8) of MPs virtually allocated inside the SA. In this article, we also exploit this concept assuming regular dispersion of MPs inside the $\mathrm{SA}$ in a grid manner with $70 \times 70 \mathrm{~m}^{2}$ distances between grid points (Table 3 ). In each of the 17,161 MPs virtually allocated inside the SA, the signal strength in the UL direction during each time period must be in compliance with the sensitivity threshold stated in Table 1 .

The problem is to find a minimum cardinality subset of powered on CSs (BSSs) with minimal energy consumption while enabling coverage and capacity demand of all TCs (UTs) which are active in each time period. To solve the stated optimization problem, we use three different binary decision variables defined as

$$
w_{i j k t}=\left\{\begin{array}{l}
1 \text { if TP } i \text { is assigned to jth CS transmitting } \\
\text { at kth Tx power level during time period } t \\
0 \text { otherwise. }
\end{array}\right.
$$

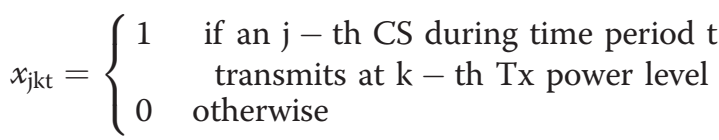$$
w_{i j k t}=\left\{\begin{array}{l}
\text { if TP } \mathrm{i} \text { is assigned to } \mathrm{j}-\text { th } \mathrm{CS} \\
\text { transmitting at } \mathrm{k}-\mathrm{th} \text { Tx power level } \\
\text { during time period } \mathrm{t} \\
0 \quad \begin{array}{l}
\text { otherwise. }
\end{array}
\end{array}\right.
$$

The first decision variables $y_{j t}$ are typical for covering problems, denoting, as part of a final solution, which CSs are active in each time period. Decision variables $x_{j k t}$ must be introduced in order to define at which Tx power level each powered on the $j$ th CS transmits during time period $t$. Variables $w_{i j k t}$ are assignment variables defining which TP $i$ is in a particular time period $t$ connected to which CS. A mathematical expression of the optimization problem is given with the next relations

$$
\begin{aligned}
\operatorname{Min} & {\left[\sum_{t} \sum_{j} P_{j} y_{j t}\left(T_{t+1}-T_{t}\right)\right.} \\
& \left.+\sum_{t} \sum_{j} \sum_{k} P_{k} x_{j k t}\left(T_{t+1}-T_{t}\right)\right] \times C_{1} \\
& +\left[\sum_{t} \sum_{j} P_{j} y_{j t}\left(T_{t+1}-T_{t}\right)\right. \\
& \left.+\sum_{t} \sum_{j} \sum_{k} P_{k} x_{j k t}\left(T_{t+1}-T_{t}\right)\right] \times C_{2}
\end{aligned}
$$

s.t.

$$
\begin{gathered}
\sum_{k} x_{j k t} \leq y_{j t} \quad \forall(j, t): j \in J=\{1, \ldots, m\}, \\
\forall t \in H=\{1, \ldots, p\}
\end{gathered}
$$

$$
\begin{aligned}
& \sum_{j} \sum_{k} a_{i j k t} x_{j k t} \geq 1 \quad \forall(i, t): i \in\{1, \ldots, n\}, \\
& \forall t \in H=\{1, \ldots, p\} \wedge \forall \mathrm{d}_{i t} \neq 0: \mathrm{a}_{i j k t} \neq 0
\end{aligned}
$$

$$
\begin{aligned}
\sum_{i \in I(j k t)} \sum_{z} \frac{d_{i t} v_{i z} w_{i j k t}}{c_{k z}} \leq 1 \quad & \forall(j, k, t): j \in J=\{1, \ldots, m\}, \\
& \forall k \in\{1, \ldots, l\} \\
& \forall t \in H=\{1, \ldots, p\}
\end{aligned}
$$

$$
\begin{array}{r}
x_{j_{b} k_{b} t}+\sum_{h=b+1}^{B} w_{i j_{h} k_{h} t} \leq 1 \quad \\
\quad \forall(i, t) i \in\{1, \ldots, n\}, \\
t \in\{1, \ldots, p\}, d_{i t} \neq 0, \\
\text { s.t } \forall: \quad 1 \leq b \leq B-1
\end{array}
$$

$$
\begin{aligned}
w_{i j_{h} k_{h} t} \leq x_{j_{b} k_{b} t} & \forall(i, t): i \in\{1, \ldots, n\}, \\
& t \in\{1, \ldots, p\}, d_{i t} \neq 0, \\
& \text { s.t } \forall: \quad 1 \leq b \leq B-1 \quad h=b
\end{aligned}
$$

$$
\begin{gathered}
\sum_{h=1}^{B} w_{i j_{h} k_{h} t}=1 \quad \forall(i, t): i \in\{1, \ldots, n\}, t \in\{1, \ldots, p\} \\
d_{i t} \neq 0, \quad h=b
\end{gathered}
$$

$$
\begin{gathered}
\sum_{j} \sum_{k} b_{s j k} x_{j k t} \geq 1 \quad \forall(s, t): s \in S=\{1, \ldots, u\}, \\
\forall t \in H=\{1, \ldots, p\}
\end{gathered}
$$




$$
\begin{array}{ll}
y_{j t} \in\{0,1\} \quad \forall j \in\{1, \ldots, m\}, \forall t \in\{1, \ldots, p\} \\
x_{j k t} \in\{0,1\} \quad \forall j \in\{1, \ldots, m\}, \forall k \in\{1, \ldots, l\}, \\
& \forall t \in\{1, \ldots, p\} \\
w_{i j k t} \in\{0,1\} \quad \forall i \in\{1, \ldots, n\}, \forall j \in\{1, \ldots, m\}, \\
& \forall k \in\{1, \ldots, l\}, \forall t \in\{1, \ldots, p\}
\end{array}
$$

Objective function (8) minimizes the monthly energy consumption (kWh/monthly) of a complete UMTS network. In the case of traffic approximations neglecting differences among traffic patterns of working and weekend days realized with seven and 24 time periods, the expression in brackets is multiplied by $C_{1}$ and $C_{2}$ transformation factors $\left(C_{1}=0.031 /\right.$ month $C_{2}=01 /$ month $)$. When approximation of the weekend and working day traffic patterns using seven time periods took place, transformation factors $C_{1}$ and $C_{2}$ have next values: $C_{1}=0.0221 /$ month and $C_{2}=0.0081 /$ month. They are used for transforming energy consumption from daily into monthly. The first term in brackets of the objective function (8) refers to the fixed component $\left(P_{j}\right)$, while the second term concerns the variable component $\left(P_{k}\right)$ of the daily network power consumption.

Ten remaining constraints (9-18) ensure that the characteristics of the proposed optimization model are as close as possible to those of the real word UMTS network. Constraints:

- (9) are coherence constraints forcing each CS to transmit using only one Tx power level,

- (10) are coverage constraints mandating that in any moment each TC must be inside the CA of at least one activated CS,

- (11) are capacity constraints which limit the total capacity of each CS according to Tx power,

- (12) are best power selection constraints forcing connection of each TC to CS from which it detects the highest signal strength,

- (13) are configuration constraints mandating that an active TC can be connected to a CS only if this CS transmits at some Tx power,

- (14) are connection constraints ensuring connection of each active TC to maximally one CS,

- (15) are coverage constraints ensuring permanent signal coverage of each MP allocated inside a complete SA,

- (16-18) are integrality constraints.

Such a set of constraints ensures that the proposed model takes into account some of the most important parameters of the UMTS networks, like capacity and coverage. Capacity constraints (11) define the maximal number of simultaneously connected voice and data users on one CSs (BSSs) transmitting at some specific Tx power. For different Tx power levels, capacity constraints perform the site capacitating through concurrent adaptation of BSS capacities regarding the maximal number of voice and data users served in parallel. By satisfying coverage constraints (15) at the position of each densely allocated MP, it is reasonable to believe that 95\% coverage of the SA is guaranteed during each time period. The presented optimization model is programmed using a prominent programming language known as A Modeling Language for Mathematical Programming.

\subsection{Instance generator}

In order to generate the network instances described in Section 4, we have developed an instance generator (IG). The IG is programmed using $\mathrm{C}++_{+}$, and data obtained at the end of the generation process are used as input data for the optimization solver. Based on a predefined set of input parameters, the IG generates analyzed UMTS network instances.

Decisions about the number of voice (TC1) and data users (TC2) that will be allocated inside the CA of a single CS (BSS) have been performed based on Table 9 developed with respect to the graphs shown in Figure 4c,d. According to these graphs, we assume capacity planning for the case of $80 \%$ network load (PL) with guaranteed $12.2 / 384 \mathrm{~kb} / \mathrm{s}$ voice/data rates. On graphs presented in Figure $4 \mathrm{c}, \mathrm{d}$, we select five graph points indicating the relationship between the maximal number of simultaneously served voice and data users. Table 9 presents chosen combinations used for allocation. The IG randomly picks one of five possible voice/data (TC1/TC2) combinations, and performs a random allocation of TCs inside the CA of each BSS. Such an approach offers randomness in dispersion of voice and data users, ensuring similarity with user dispersion characteristics for real networks. In addition, with this approach to TC allocation, we ensure consistency in network capacity planning which is close to the real ones.

\section{Numerical results}

Optimization results have been obtained at the output of a state of the art CPLEX optimization solver. For each analyzed network instance, we obtain three optimization results; one per envisioned service type defined as

Table 9 Combinations for generation of TCs inside CA of a single BSS

\begin{tabular}{llllllllllll}
\hline TC type & \multicolumn{4}{c}{ One-sector } & BSS & & TC type & \multicolumn{4}{c}{ Three-sector BSS } \\
\hline TC1 & 0 & 1 & 2 & 3 & 4 & TC1 & 0 & 3 & 6 & 9 & 10 \\
TC2 & 18 & 13 & 9 & 4 & 0 & TC2 & 51 & 36 & 21 & 6 & 0 \\
\hline
\end{tabular}


combination of voice $(12.2 \mathrm{~kb} / \mathrm{s})$ and one $(64 / 128 / 384$ $\mathrm{kb} / \mathrm{s}$ ) data service. Since we separately analyzed six different one-sector and three-sector instances for three different combinations of traffic pattern approximations, we obtained 108 optimization results in total. We believe that such a number of obtained results and analyzed instances is enough to prove consistency of the proposed optimization concept. In order to reduce the complexity of the proposed optimization model, in our analyses we neglected the influence of transients from the off to the on state of BSSs. Hence, optimization problem of every analyzed network instance has been solved to the optimum, within a reasonable computational time.

\subsection{Visualization of obtained results}

Visualization of the optimization results obtained for traffic approximation with 24 time periods has been presented in Figure 5. This example presents visualization during the second time period $(t=2)$ having only $18 \%$ of active TCs (Table 5). For the case of Instance 4, which consisted of one-sector BSSs, Figure $5 \mathrm{a}, \mathrm{c}, \mathrm{e}$ presents visualization of results obtained while ensuring voice/data service rates equal to $12.2 / 64,12.2 / 128$, and $12.2 / 384 \mathrm{~kb} / \mathrm{s}$, respectively. Similarly, Figure $5 \mathrm{~b}, \mathrm{~d}, \mathrm{f}$ visualizes optimization results of the Instance 10 with three-sector BSSs offering the same service rate combinations. Two reasons motivate us to visualize optimization results for the time period $(t=2)$ with such low percentage of active users (TCs).

The first reason is to show results for the time period during which the highest number of CSs (BSSs) will be in the powered off state. This is presented in Table 10 for traffic approximation performed using 24 discrete time periods in 1 day. According to Figure 5, a considerable number of macro CSs (8 out of 33) are in the powered off state. Active users (TCs) inside CAs of those powered off CSs have been connected to the conceivable powered on CSs. However, slight differences among instances offering different service rates can be noticed regarding the locations of the powered off CSs. This consequently influences on the topology of established wireless connections between TPs and CSs. For example, in the case of results presented for one-sector and three-sector BSSs in Figure 5e,f, somewhat different establishments of wireless connections can be perceived if compared with those on Figure $5 \mathrm{c}, \mathrm{d}$, respectively. This is due to the differences in guaranteed service rates, where Figure $5 \mathrm{e}, \mathrm{f}$ shows optimization results for network instances that must ensure the highest data rates $(384 \mathrm{~kb} / \mathrm{s})$.

Regarding the second reason, it must be emphasized that with the presented visualization we confirm that even during the time period having the highest percentage (24.5\%) of powered off BSSs, each of the analyzed networks preserved full SA coverage. Table 10 gives detailed information about the number and percentage of the powered off CSs for Instance 10 during 1 day. Even if we take into consideration time periods with the lowest number of active users (e.g. $t=5,6$ in Table 5), the percentage of powered off CSs according to Table 10 remains unchanged (24.2\%). Therefore, full coverage of the SA with radio signal will not be lost in any moment during a day. This is one of the most important criteria when implementing energy-efficient network management.

To ensure full SA coverage, the network management system is forced to keep powered on CSs in those areas lacking any active TCs (Figure 5). This is the reason why during time periods with lowest user activity, the number of powered off CSs presented in Table 10 cannot be higher than eight. Hence, it is not possible, for the purpose of increasing energy efficiency, to simply shut down those BSSs temporarily missing active users, since this can lead to coverage holes lacking any service accessibility. Conclusions obtained for the two presented network instances are equal to those obtained for other analyzed instances.

\subsection{Impact of service rates on power consumption}

In order to evaluate the quality of the obtained optimization results, we have introduced a reference model $(\mathrm{RM})$ as a term describing modern cellular networks. The RM is a network model with working properties typical of the radio side of already deployed UMTS networks. This means that for the RM we assume permanent transmission of BSs at the maximal Tx power equal to $40 \mathrm{~W}$. In addition, BSs cannot dynamically be shut down and powered on in accordance with the traffic pattern changes and there are no adaptations of $\mathrm{Tx}$ power in order to ensure targeted service rates. Consequently, it is assumed that each one-sector BSS in the RM continuously consumes $596 \mathrm{~W}$, while each threesector BSS consumes $1858 \mathrm{~W}$ (Table 4). The selected values are taken from Table 4 and they correspond to the instantaneous power consumptions of the one-sector and three-sector BSSs in the case of transmitting at the maximal Tx power $(40 \mathrm{~W})$. With such an approach, it is possible to perform a comparison of the obtained optimization results with the power consumption of modern day networks represented with the RM.

As an example case, Figure 6 shows changes in instantaneous power consumption of a complete UMTS network for Instances 6 and 12. Changes are presented on hourly bases during 1 day and similar patterns have been obtained for other analyzed instances. On both Figure 6a,b, maximal instantaneous power consumptions during the peak hours are lower than the constant instantaneous power consumption of the RM. This is because the RM represents a traditional UMTS network planning approach, primarily dedicated to accommodating 

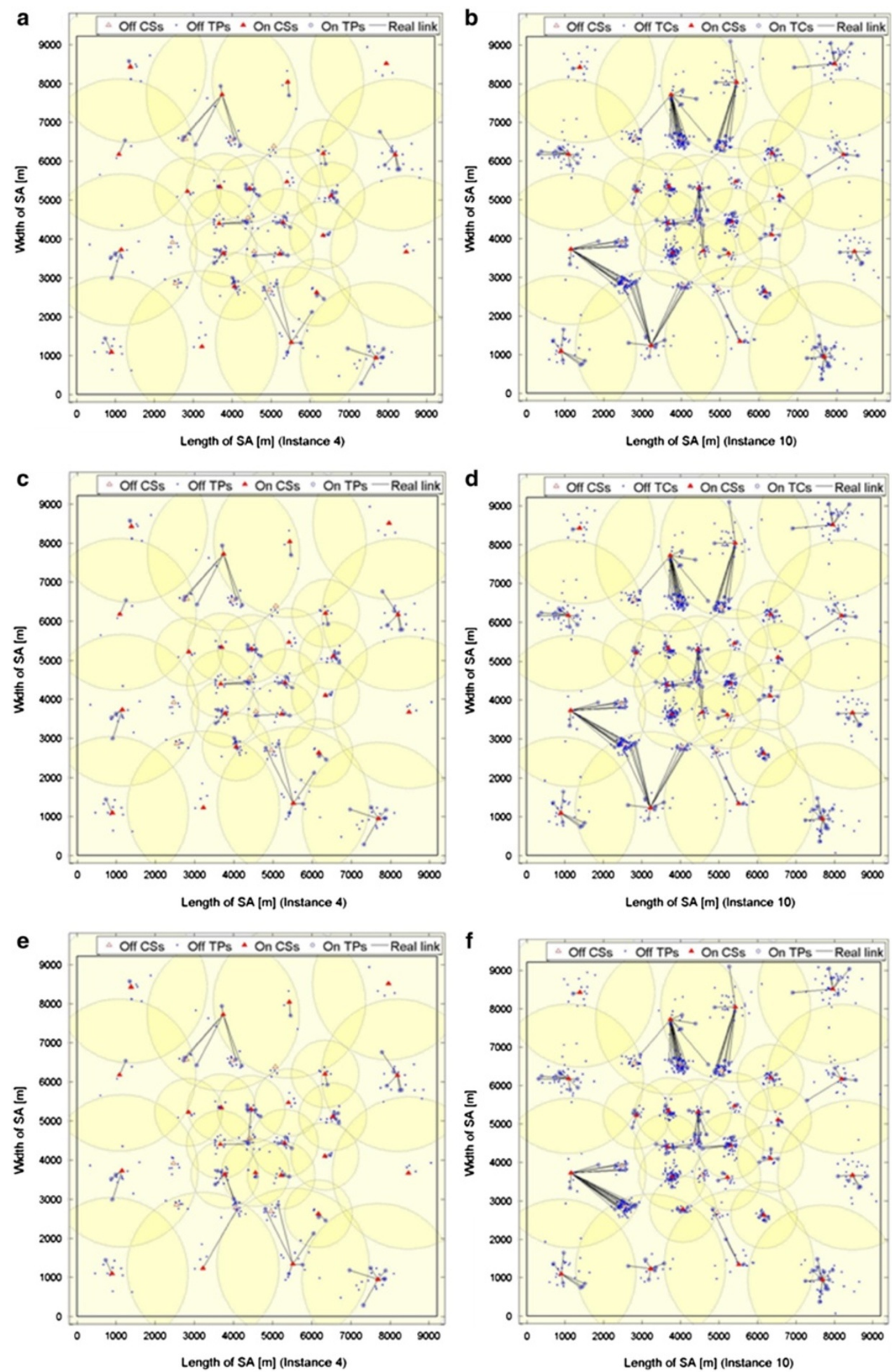

Figure $\mathbf{5}$ (See legend on next page.) 
(See figure on previous page.)

Figure 5 Visualization of optimization results for Instance 4 (one-sector BSSs) with guaranteed voice/data rates: (a) 12.2/64 kb/s, (c) $12.2 / 128 \mathrm{~kb} / \mathrm{s}$, (e) $12.2 / 384 \mathrm{~kb} / \mathrm{s}$; visualization of optimization results for Instance 10 (three-sector BSS) with guaranteed voice/data rates: (b) $12.2 / 64 \mathrm{~kb} / \mathrm{s}$, (d) $12.2 / 128 \mathrm{~kb} / \mathrm{s}$, (f) $12.2 / 384 \mathrm{~kb} / \mathrm{s}$.

the MAL. In practice, the PL during peak hours is generally lower than the MAL. This is the reason for the optimization model for Instances 6 and 10 resulting in lower instantaneous power consumptions when compared with the RM.

Figure 6 also shows that with the proposed optimization approach, we managed to modulate the instantaneous network power consumption according to the traffic pattern changes. This results in significantly lower average instantaneous power consumption of the network during 1 day when compared with the RM power consumption. general, network power consumption becomes higher during periods with a higher percentage of active users and decreases when user activity diminishes (Figure 6). This decrease in the network power

Table 10 Statistics of powered off CSs (BSSs) during period of 1 day for instance 10

\begin{tabular}{|c|c|c|c|}
\hline \multirow{2}{*}{$\begin{array}{l}\text { Time period } \\
t(h h-h h)\end{array}$} & \multicolumn{3}{|c|}{ Number/\% of powered off BSSs } \\
\hline & $12.2 / 64 \mathrm{~kb} / \mathrm{s}$ & $12.2 / 128 \mathrm{~kb} / \mathrm{s}$ & $12.2 / 384 \mathrm{~kb} / \mathrm{s}$ \\
\hline $1(00-01)$ & $8 / 24.2$ & 8/24.2 & 8/24.2 \\
\hline $2(01-02)$ & $8 / 24.2$ & $8 / 24.2$ & $8 / 24.2$ \\
\hline $3(02-03)$ & $8 / 24.2$ & $8 / 24.2$ & $8 / 24.2$ \\
\hline $4(03-04)$ & $8 / 24.2$ & $8 / 24.2$ & $8 / 24.2$ \\
\hline $5(04-05)$ & $8 / 24.2$ & $8 / 24.2$ & $8 / 24.2$ \\
\hline $6(05-06)$ & $8 / 24.2$ & $8 / 24.2$ & $8 / 24.2$ \\
\hline $7(06-07)$ & $8 / 24.2$ & $8 / 24.2$ & $8 / 24.2$ \\
\hline $8(07-08)$ & $8 / 24.2$ & $8 / 24.2$ & $8 / 24.2$ \\
\hline $9(08-09)$ & $8 / 24.2$ & $8 / 24.2$ & $8 / 24.2$ \\
\hline 10(09-10) & $8 / 24.2$ & $8 / 24.2$ & $8 / 24.2$ \\
\hline $11(10-11)$ & $7 / 21.2$ & $7 / 21.2$ & $6 / 18.1$ \\
\hline $12(11-12)$ & $7 / 21.2$ & $5 / 15.1$ & $4 / 12.1$ \\
\hline $13(12-13)$ & $5 / 15.1$ & $5 / 15.1$ & 3/9.1 \\
\hline $14(13-14)$ & $5 / 15.1$ & 5/15.1 & $1 / 3$ \\
\hline $15(14-15)$ & 4/12.1 & $3 / 9.1$ & $0 / 0$ \\
\hline $16(15-16)$ & $3 / 9.1$ & $3 / 9.1$ & $0 / 0$ \\
\hline $17(16-17)$ & $3 / 9.1$ & $3 / 9.1$ & $0 / 0$ \\
\hline $18(17-18)$ & 5/15.1 & 4/12.1 & $2 / 6.1$ \\
\hline 19(18-19) & 5/15.1 & 5/15.1 & $3 / 9.1$ \\
\hline 20(19-20) & $7 / 21.2$ & $6 / 18.1$ & $2 / 6.1$ \\
\hline $21(20-21)$ & $5 / 15.1$ & 5/15.1 & $1 / 3$ \\
\hline $22(21-22)$ & 618.1 & 5/15.1 & 4/12.1 \\
\hline $23(22-23)$ & $8 / 24.2$ & $8 / 24.2$ & 6/18.1 \\
\hline $24(23-00)$ & $8 / 24.2$ & $8 / 24.2$ & $7 / 21.2$ \\
\hline
\end{tabular}

consumption is primarily followed with an increase in the number of powered off CSs, as presented in Table 10. Since the one-sector BSS consumes nearly three times less power than the three-sector BSS (Table 4), instantaneous network power consumptions expressed in $\mathrm{kWh}$ on Figure 6 are almost three times higher for Instance 10, having three-sector BSSs.

Modulation of the instantaneous network power consumption in accordance with the traffic pattern variations is directly reflected in a coefficient of network energy savings, expressed on samples with 1-h duration. Changes in the coefficients of energy savings on an hourly basis during a day have been presented in Figure 7a,b for the one-sector and three-sector BSSs, respectively. Such coefficients are calculated as the ratio of hourly network energy consumptions obtained for analyzed optimization model and RM during each time period. According to Figure 7, lower energy savings have been obtained for the time periods characterized with higher percentages of active users (TCs) and vice versa. During hours of very high user activity (from 13:00 to 18:00 h), the coefficient of energy savings becomes low. For the case of guaranteed $12.2 / 384 \mathrm{~kb} / \mathrm{s}$ service rates, Figure $7 \mathrm{~b}$ shows a fall in the energy savings coefficient to approximately $10 \%$. This is because the network must accommodate increased user traffic, which results in reductions in the number of powered off CSs and consequently in a lower energy savings coefficient. Such a decrease in the number of powered off CSs during peak hours can even reach the value of zero, as presented in Table 10 for the case $12.2 / 384 \mathrm{~kb} / \mathrm{s}$ rates. Therefore, dynamic adaptation of BS Tx power should not be neglected, since such a factor contributes to reductions of the monthly energy consumption.

On the other hand, the highest hourly energy savings, reaching $50 \%$, have been obtained during morning hours from 02:00 to 07:00 h. If we consider only traffic pattern variations, the coefficient of energy savings could hypothetically reach even higher values during low activity hours. But, for the reason of ensuring full SA coverage explained previously, the coefficient in Figure $7 \mathrm{a}, \mathrm{b}$ remains unchanged for all time periods with less than $20 \%$ of active TCs.

\subsection{Impact of service rates on energy savings}

Influence of guaranteed service rates on instantaneous network power consumption is significant, which can be perceived from Figure 6. For the same network instance in terms of allocated TPs and BSSs, ensuring higher 

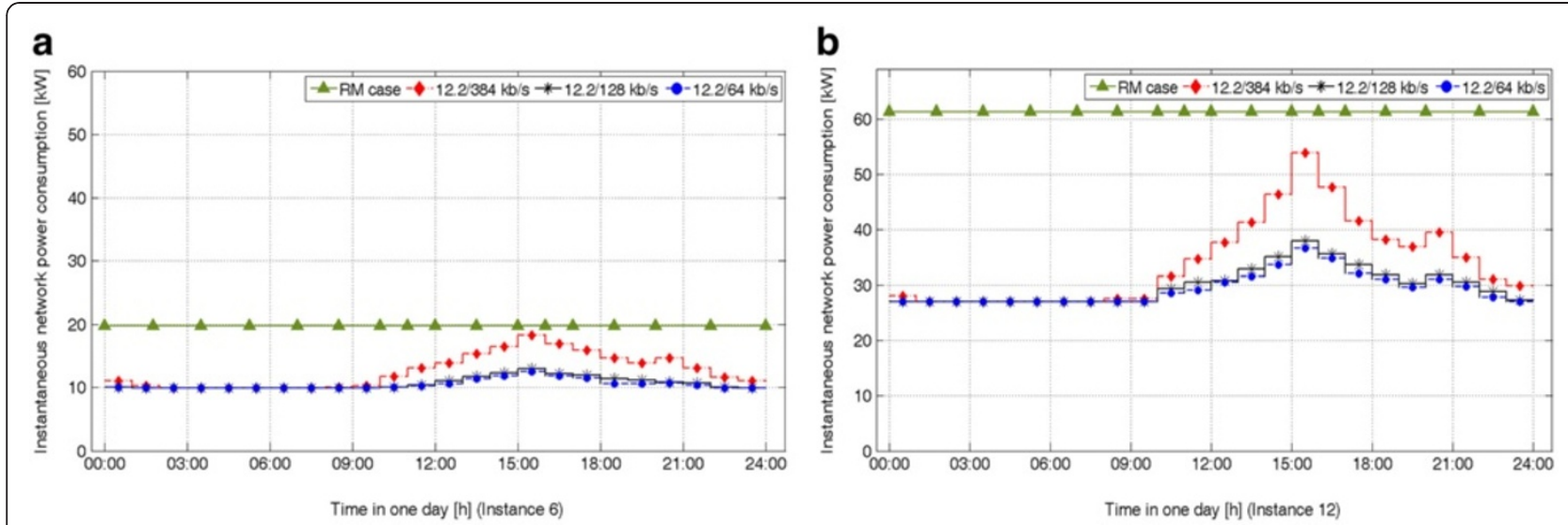

Figure 6 Variations in instantaneous network power consumption for instance with (a) one-sector BSSs, (b) three-sector BSSs.

service rates along a complete SA results in a higher network power consumption. This is directly reflected in the values of monthly energy consumption presented for each of the analyzed instances in Figure 8. Reason why $12.2 / 384 \mathrm{~kb} / \mathrm{s}$ voice/data service causes the highest monthly energy bill can be found in the necessity of activating the highest volume of network resources during one month to accommodate more demanding service rates. In the case of ensuring lower service rates, the volume of network resources regarding the average number of powered on CSs and the level of Tx power engaged during a month can be lower. This results in a lower monthly energy consumption, presented in Figure 8 for $12.2 / 64$ and $12.2 / 128 \mathrm{~kb} / \mathrm{s}$ services.

Reasons for the relatively small differences among monthly energy consumptions of the same instances offering $12.2 / 64$ and $12.2 / 128 \mathrm{~kb} / \mathrm{s}$ rates (Figure 8 ) can be found in the network capacity planning approach. In Sections 5 and 7, we emphasize that the allocation of TCs inside CAs of each BSS has been performed assuming guaranteed $12.2 / 384 \mathrm{~kb} / \mathrm{s}$ service rates for an $80 \%$ network load (PL). Since we use the same instance in terms of number and allocations of TCs when examining influence on network consumption of the other two rate combinations, the network will be over-capacitated in the case of ensuring a $12.2 / 64 \mathrm{~kb} / \mathrm{s}$ service rate. Due to excessive network capacity, guaranteeing $12.2 / 64 \mathrm{~kb} / \mathrm{s}$ rates will have a slightly lower influence on monthly energy consumptions when compared with the influence caused by $12.2 / 128 \mathrm{~kb} / \mathrm{s}$ rates. To have higher influence on monthly energy consumption, a higher number of users should be allocated inside the SA when $12.2 / 64 \mathrm{~kb} / \mathrm{s}$ rates will be guaranteed. But, an increase in the number of allocated TCs results in a completely new instance, which eliminates the possibility of making a comparison among guaranteed service rates for the same instance.

Nevertheless, it can clearly be noticed from Figure 8 that ensuring higher service rates imposes higher network energy consumption, even when energy-efficient resource management is used. This is an extremely important cognition when developing future energy-efficient cellular network systems which must satisfy the constant pressure
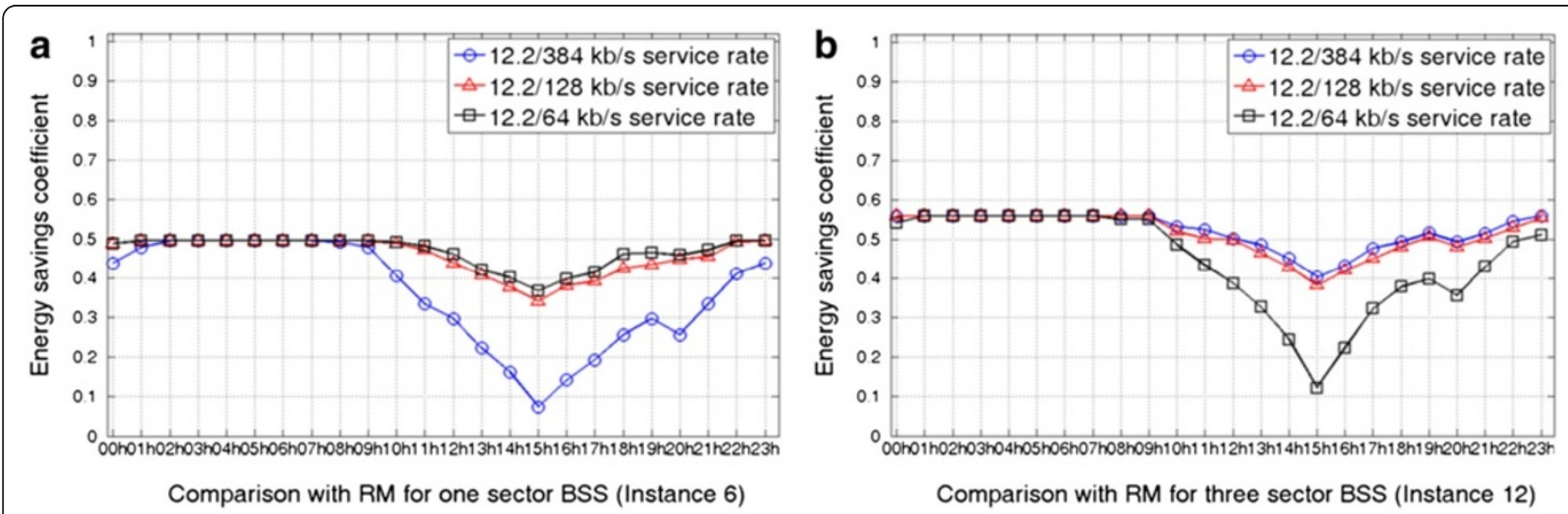

Figure 7 Changes of energy savings coefficient for different service rates in case of instance with (a) one-sector BSSs, (b) three-sector BSSs. 

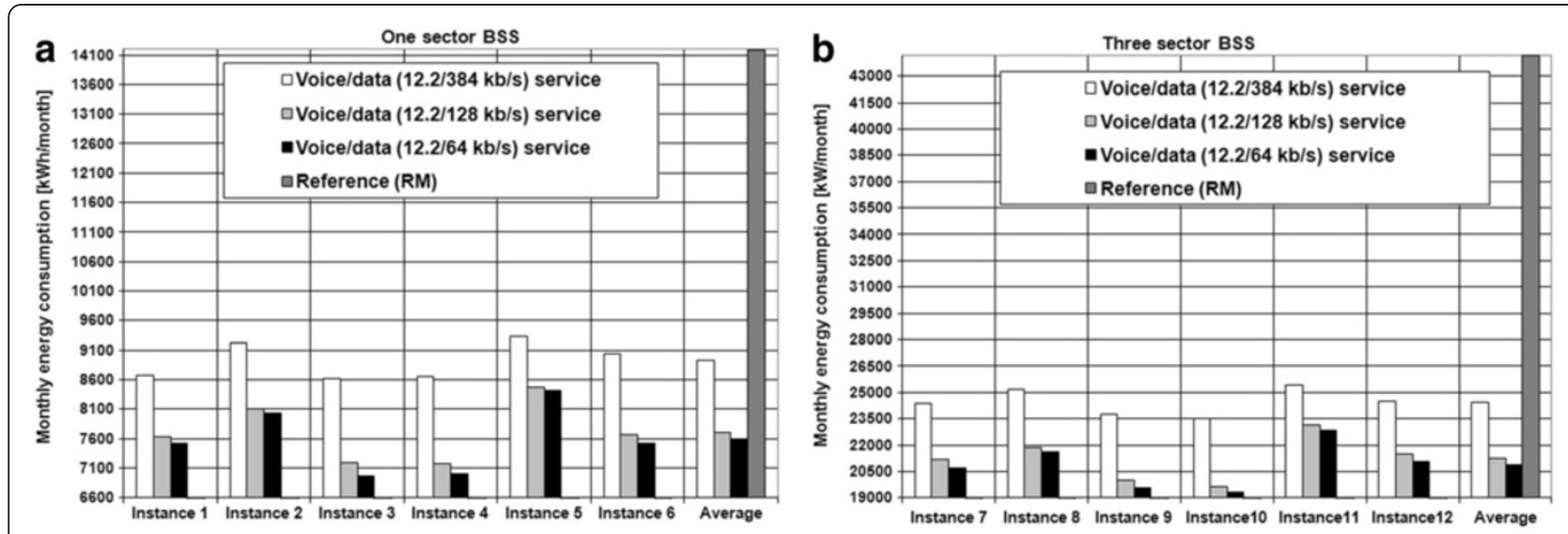

Figure 8 Statistic of monthly energy consumption for instances with (a) one-sector BSSs and (b) three-sector BSSs.

of ensuring higher service rates to mobile users. Statistics presented in Figure 8a,b show variations in monthly energy consumption among analyzed one-sector and three-sector instances, respectively. These differences are primarily due to the fact that we analyze different onesector and three-sector instances in terms of allocation of BSSs and TCs (users). In addition, the differences among instances regarding the overall number of randomly allocated TCs (Table 3) also contribute to the variations in the total monthly energy consumption. The rightmost vertical bars in Figure 8 indicate the monthly energy consumption of the RM and average consumptions of all analyzed instances while guaranteeing corresponding service rates. We performed averaging of the monthly energy consumption since each of the one-sector and three-sector instances have the same number of macro BSSs with the possibility of transmitting using the same set of Tx powers.

When compared with monthly energy consumption of the RM, each one-sector or three-sector instance has significantly lower monthly consumptions (Figure 8).
Obviously, higher differences in monthly consumption can be noticed in Figure $8 \mathrm{~b}$ for instances with threesector BSSs, simply due to a higher initial power consumption of the three-sector BSS (Table 4). For example, differences between the monthly energy consumption of the RM and averaged one-sector and three-sector instances when ensuring 12.2/128 kb/s service rates are equal to $6,468.85$ and $22,929.35 \mathrm{kWh}$, respectively. Translated into ecological benefits and financial savings, this equates to an annual reduction in emitted $\mathrm{CO}_{2}$ of approximately 46 and 162 metric tons and with yearly savings on the energy bill equal to $124,201.92 €$ and $440,243.52 €(1.6 € / \mathrm{kWh})$, respectively. Since most modern day networks have been deployed as a combination of a smaller number of one-sector and a higher number of multi (three) sector macro sites, operator savings in terms of energy consumption are much closer to the values obtained for the averaged case having three-sector BSSs. Figure 9 shows percentages of monthly energy savings for each of the analyzed instances, obtained through comparison with the monthly energy consumption of the
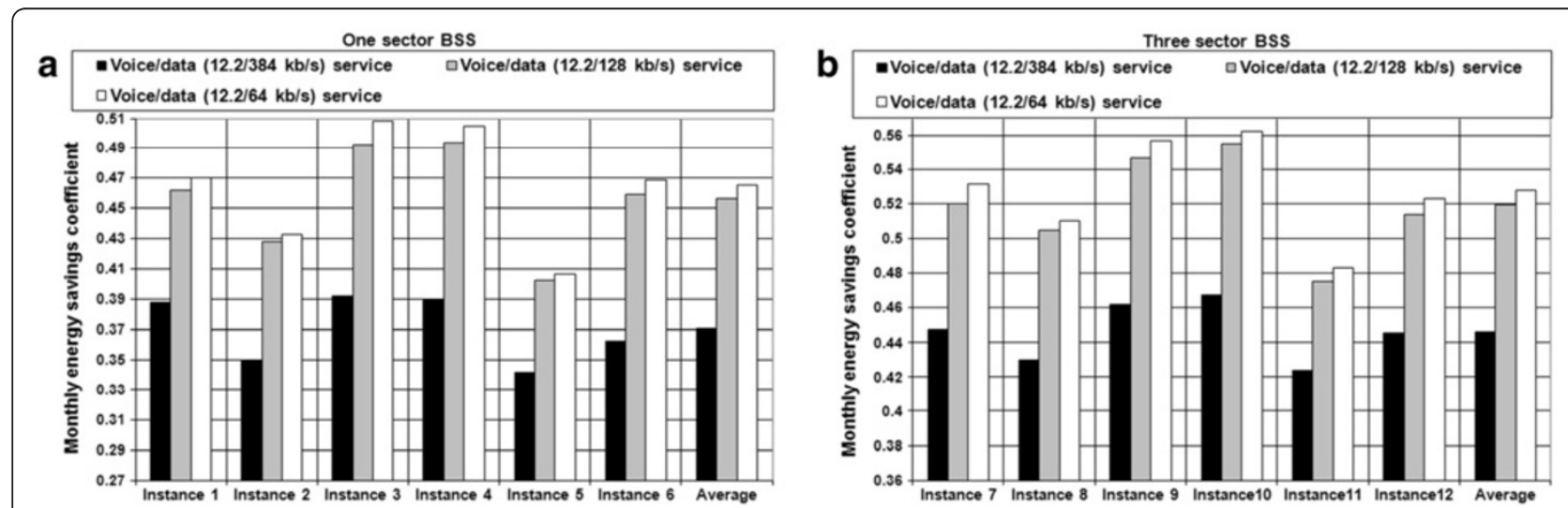

Figure 9 Coefficients of monthly energy savings for instances with (a) one-sector BSSs and (b) three-sector BSSs. 

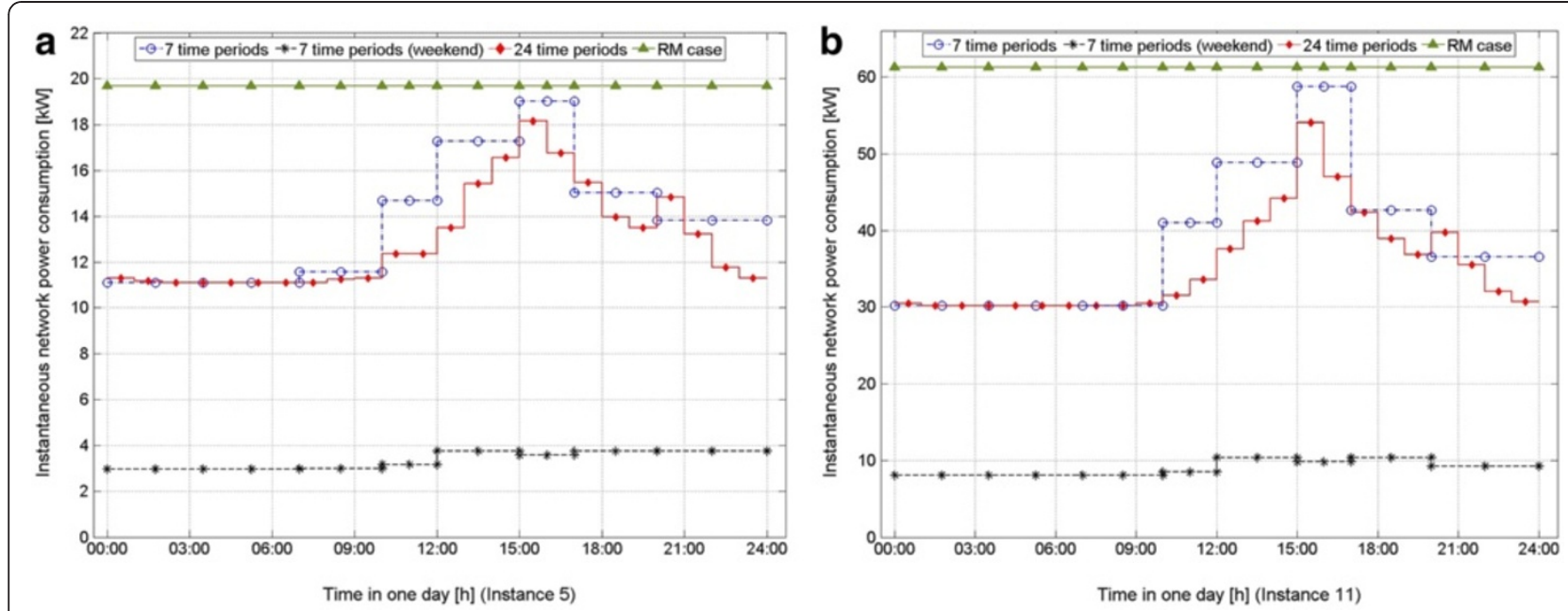

Figure 10 Variations in instantaneous network power consumption for guaranteed voice/data service rates equal to $12.2 / 384 \mathrm{~kb} / \mathrm{s}$ in case of (a) one-sector BSS (Instance 5), (b) three-sector BSS (Instance 11).

RM. According to Figure 9, the proposed energy-efficient network management scheme, based on dynamic scaling of Tx power and on/off state of BSSs, gives remarkable savings in monthly network energy consumption. For the case of one-sector instances, reductions in monthly energy consumption range from 35 to $50 \%$, while even higher percentages ranging from 43 to $57 \%$ have been obtained for instances with three-sector BSSs.

\subsection{Impact of switching granularity on power consumption}

Figure 10 presents four instances with one-sector and three-sector BSSs changes in the daily power consumption for different traffic pattern approximations. It can be seen that switching granularity influences on instantaneous network power consumption. When compared with traffic approximation based on 7 time periods, approximation with 24 time periods offers lower energy consumption during periods of higher user activity (08:00-24:00). This is because finer-grained temporal control of network resources enables better adaptation to time and space traffic pattern changes. As a consequence, this results in lower instantaneous power consumption of the network. In the period of low user activity (24:00-08:00), the network can keep QoS in terms of coverage and capacity with minimum activated resources. As a result, higher switching granularity in such periods does not have significant influence on the instantaneous power consumption.

According to the results presented in Figure 10, the optimal solution in terms of switching frequency during a day could be higher granularity in the periods of higher
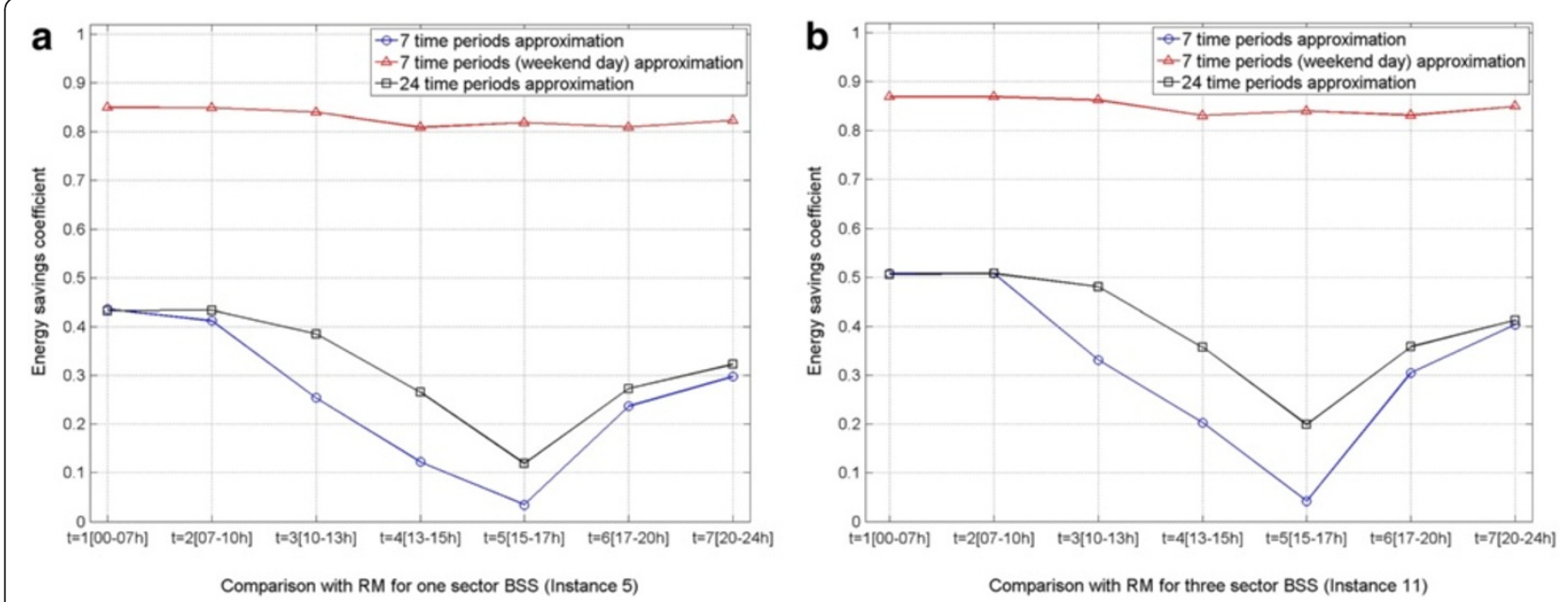

Figure 11 Trends in changes of energy savings coefficient for guaranteed voice/data service rates equal to $12.2 / 384 \mathrm{~kb} / \mathrm{s}$ in the case of (a) one sector BSS (Instance 5), (b) three sector BSS (Instance 11). 
user activity and very low granularity during periods characterized with low user activity. In addition, from the results presented in Figure 10, it can be perceived that one-sector or three-sector network instances have significantly lower instantaneous power consumption during a weekend day, when compared with consumption during a working day. Therefore, switching granularity in periods of higher user activity during a weekend day can be lower than switching granularity during a working day. Changes in the coefficient of energy savings during a day for three traffic pattern approximations presented in Figure 11 confirm these statements. Figure 11 indicates higher energy savings during a weekend day. This is due to the lower amount of network resources that need to be activated to accommodate lower user activity during a weekend day. However, higher energy-saving coefficients in the period of higher user activity during a working day have been obtained when higher switching granularity is
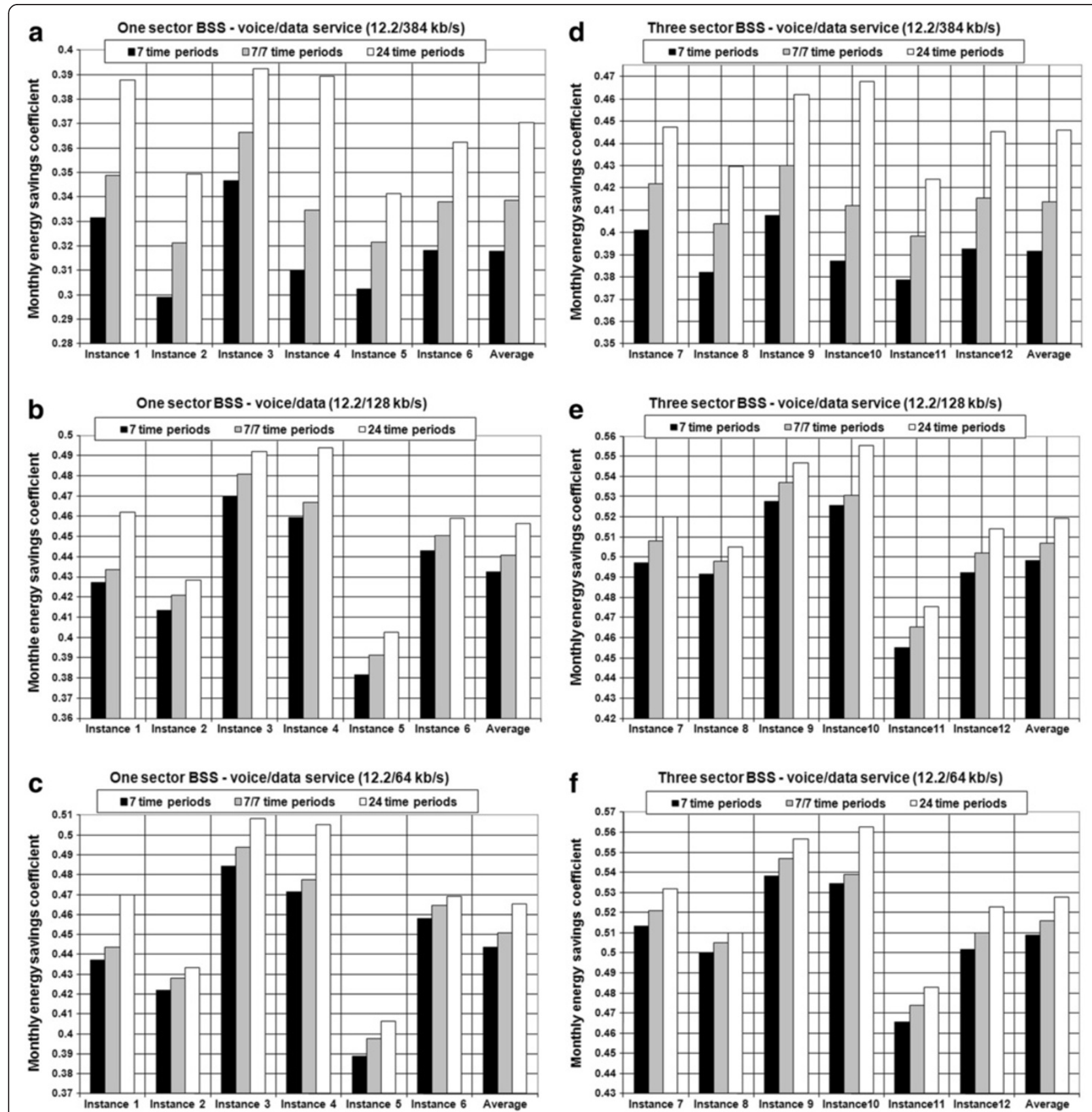

Figure 12 Coefficient of monthly energy savings for each of analyzed one and three sector BSS instance in case of voice/data service with guaranteed rates equal to (a, d) $12.2 / 384 \mathrm{~kb} / \mathrm{s}$, (b, e) $12.2 / 128 \mathrm{~kb} / \mathrm{s}$, (c, f) $12.2 / 64 \mathrm{~kb} / \mathrm{s}$. 
used. This is further confirmation that higher energy savings can be obtained if finer-grained temporal control is used in these periods.

\subsection{Impact of switching granularity on energy savings}

Figure 12 indicates the influence of switching granularity on monthly energy savings for all the combinations of voice/data service rates. In general, it can be said that higher switching granularity leads to larger monthly energy savings. It is worth emphasizing that vertical bars for $7 / 7$ time periods indicate coefficients of monthly energy savings taking into account different traffic patterns of weekend and working days. In comparison with traffic approximation neglecting weekend days (7 time periods), higher energy savings between 0.5 and $2.5 \%$ per month can be perceived when traffic patterns of weekend days are considered. Even larger differences, ranging between 3 and $5.5 \%$, can be seen among coefficients of energy savings obtained for traffic approximations with lower (7 time periods) and higher (24 time periods) switching granularity. As an example, we emphasize three-sector Instance 10 for $12.2 / 384 \mathrm{~kb} / \mathrm{s}$ voice/data service rates with differences in energy consumption on a yearly level equal to $42,590.16 \mathrm{kWh}$. Translated into financial savings, this leads to a $68,144.25 €$ annual reduction at the network level. Considering the obtained energy savings, switching granularity will play an important role in the development of energy-efficient network management algorithms. In order to achieve the highest monthly energy savings, switching frequencies of BSs must be closely integrated with the intensity of traffic changes.

\section{Conclusion}

In this article, we have presented a novel optimization model which can be used for energy-saving purposes at the level of a complete cellular access network. The proposed model was tested on a set of real size UMTS network instances, generated using a specially developed IG. This article shows that the proposed model ensures full SA coverage and the targeted service rate requirement through dynamic radio resource management. According to obtained numerical results, remarkable monthly energy savings between 35 and 57\% can be obtained, if dynamic BSS switching accompanied with Tx power scaling is implemented in UMTS networks.

The main contribution of this article is the presentation of the influence of BSs switching granularity on the possible reductions of network energy consumption in the time domain. We show that appropriate selection of BSs switching granularity during different periods of working and weekend days can result in significant monthly energy savings. In addition, in this article, we analyze the influence of introducing higher service rates on energy savings potential. Providing higher service rates to the users results in a higher network energy consumption, even when the same energy-efficient network management is in use. Such a cognition additionally emphasizes the need for development of the holistic approaches focused on maximizing energy savings, since future cellular networks will certainly be even more throughput demanding.

Our further research activity will be focused on investigating energy-saving potential when implementing energy-efficient management in the heterogeneous cellular networks consisted of macro, micro, and pico/femto cells. Also, the influence on energy savings of switching the BSs transients from the off to the on states will be investigated more deeply.

\section{Competing interests}

The authors declare that they have no competing interests.

\section{Acknowledgments}

The authors would like to thank Massimo Bogarelli from Politecnico di Milano for assisting us during research process.

\section{Author details}

${ }^{1}$ FESB-Faculty of Electrical Engineering, Mechanical Engineering and Naval Architecture, University of Split, Croatia, R. Boskovica b.b, Split 21000, Croatia. ²DEl, Politecnico di Milano, Via Ponzio 34/5, 20133, Milano, Italy.

Received: 8 July 2012 Accepted: 24 October 2012

Published: 16 November 2012

\section{References}

1. B Gammage, Gartner's Top Predictions for IT Organizations and Users, 2010 and Beyond: A New Balance, (Gartner 2009) (2011). http://www.gartner.com. Accessed 20 September

2. M Etoh, T Ohya, Y Nakayama, Energy consumption issues on mobile network systems, in Proceedings of the International Symposium on Applications and the Internet SAINT 2008 (2008)

3. G Fettweis, E Zimmermann, ICT energy consumption-trends and challenges, in Proceedings of the 11th International Symposium on Wireless Personal Multimedia Communications - WPMC (Lapland, Finland, 2008)

4. R Tafazolli, V Mattila, eMobility Mobile and Wireless Communications Technology Platform: Strategic Research Agenda, Version 7 (2008). http://www. emobility.eu.org, Accessed 1 May 2011

5. T Chen, $\mathrm{H}$ Zhang, Z Zhao, X Chen, Towards green wireless access networks, in Proceedings of the 7th International ICST Conference on Communications and Networking in China (CHINACOM) (Beijing, China, 2010)

6. C Ha, T Harrold, S Armour, I Krikidis, S Videv, PM Grant, H Haas, JS Thompson, I Ku, C-X Wang, AL Tuan, MR Nakhai, Z Jiayi, L Hanzo, Green radio: radio techniques to enable energy-efficient wireless networks. IEEE Commun Mag 49(6), 46-54 (2011). doi:10.1109/MCOM.2011.5783984

7. LM Correia, D Zeller, O Blume, D Ferling, Y Jading, I Gódor, G Auer, $L$ Van Der Perre, Challenges and enabling technologies for energy aware mobile radio networks. IEE Commun Mag 48(11), 66-72 (2010). doi:10.1109/ MCOM.2010.5621969

8. D Ferling, T Bitzer, T Bohn, D Wiegner, A Pascht, Power efficient transceivers to enable energy-efficient mobile radio systems. Bell Labs Tech J 15(2), 59-76 (2010). doi:10.1002/bltj.20441

9. S Roy, Energy logic for telecommunications, A White Paper Emerson Network Power Energy Systems (2008). http://www.eqlfiles.com/20090615/pdf/ Emerson-Q2-Energy-Logic-fo.pdf, Accessed 28 June 2011

10. D Hernon, Enhanced energy efficiency and reliability of telecommunication equipment with the introduction of novel air cooled thermal architectures. Bell Labs Tech J 15(2), 31-51 (2010). doi:10.1002/blti.20439

11. H Bogucka, A Conti, Degrees of freedom for energy savings in practical adaptive wireless systems. IEEE Commun Mag 49(6), 38-45 (2011). doi:10.1109/MCOM.2011.5783983 
12. L Saker, S-E Elayoubi, T Chahed, Minimizing energy consumption via sleep mode in green base station, in IEEE Wireless Communications and Networking Conference - WCNC (Sydney, Australia, 2010). 18-21 April 2010

13. J Lorincz, A Capone, M Bogarelli, Energy savings in wireless access networks, in Proceedings of 5th International Symposium on Wireless Pervasive Computing - ISWPC 2010 (Modena, Italy, 2010)

14. J Lorincz, A Capone, D Begusic, Optimized network management for energy savings of wireless access networks. Comput Netw J 55(3), 514-540 (2011). doi:10.1016/j.comnet.2010.09.013

15. J Lorincz, A Capone, D Begusic, Heuristic algorithms for optimization of energy consumption in wireless access networks. KSII Trans Internet Inf Syst J 5(4), 626-648 (2011). doi:10.3837/tiis.2011.04.001

16. J Lorincz, M Bogarelli, A Capone, D Begusic, Heuristic approach for optimized energy savings in wireless access networks, in Proceedings of the 18th International Conference on Software, Telecommunications and Computer Networks - SoftCOM 2010 (Split-Bol, Croatia, 2010)

17. L Chiaraviglio, D Ciullo, M Meo, MA Marsan, Energy-aware UMTS access networks, in Proceedings of the 11th International Symposium on Wireless Personal Multimedia Communications - WPMC 2008 (Lapland, Finland, 2008)

18. MA Marsan, L Chiaraviglio, D Ciullo, M Meo, Optimal energy savings in cellular access networks, in First International Workshop on Green Communications - GreenComm'09 (Dresden, Germany, 2009)

19. O Blume, H Eckhardt, S Klein, E Kuehn, WM Wajda, Energy savings in mobile networks based on adaptation to traffic statistics. Bell Labs Tech J 15(2), 77-94 (2010). doi:10.1002/bltj.20442

20. E Oh, B Krishnamachari, X Liu, Z Niu, Toward dynamic energy-efficient operation of cellular network infrastructure. IEEE Commun Mag 49(6), 56-61 (2011). doi:10.1109/MCOM.2011.5783985

21. K Dufková, M Bjelica, M Byongkwon, L Kencl, J-Y Le Boudec, Energy savings for cellular network with evaluation of impact on data traffic performance, in Proceedings of the 16th European Wireless Conference - EW (Lucca, 2010). 12-15 April 2010

22. E Oh, B Krishnamachari, Energy Savings through Dynamic Base Station Switching in Cellular Wireless Access Networks, in Proceedings of the Global Communication Conference (GLOBECOM 2010) (Miami, FL, USA, 2010)

23. Z Niu, Y Wu, J Gong, Z Yang, Cell zooming for cost-efficient green cellular networks. IEEE Commun Mag 48(11), 74-79 (2010). doi:10.1109/ MCOM.2010.5621970

24. S Videv, JS Thompson, H Haas, PM Grant, Resource allocation for energy efficient cellular systems. EURASIP J Wirel Commun Netw 181, 1-15 (2012) doi:10.1186/1687-1499-2012-181

25. Y Huang, J Xu, L Qiu, An energy efficient semi-static power control and link adaptation scheme in UMTS HSDPA. EURASIP J Wirel Commun Netw 87, 1-13 (2012). doi:10.1186/1687-1499-2012-87

26. L Suarez, L Nuaymi, JM Bonnin, An overview and classification of research approaches in green wireless networks. EURASIP J Wirel Commun Netw 142, 1-18 (2012). doi:10.1186/1687-1499-2012-142

27. C Smith, D Collins, 3G Wireless Networks (McGrow-Hill Companies, 2002)

28. IS Seybold, Introduction to RF Propagation (Wiley \& Sons, New York, 2005)

29. TS Rappaport, Wireless Communications: Principles and Practice, 2nd edn. (Prentice Hall PTR, Englewood Cliffs, NJ, 2001)

30. J Lempiäinen, M Manninen, Radio Interface System Planning for GSM/GPRS/ UMTS (Kluwer Academic Publishes, Amsterdam, 2001)

31. 3GPP TS 25.101, User Equipment (UE) radio transmission and reception (FDD), 3rd Generation Partnership Project. http://www.3gpp.org/ftp/Specs/html-info/ 25-series.htm, Accessed 1 May 2012

32. 3GPP TS 25.104, Base Station (BS) radio transmission and reception (FDD), 3rd Generation Partnership Project (2012). http://www.3gpp.org/ftp/Specs/htmlinfo/25-series.htm, Accessed May 1

33. J Lorincz, T Garnma, G Petrovic, Measurements and modelling of base station power consumption under real traffic loads. Sensors J 12(4), 4281-4310 (2012). doi:10.3390/s120404281

34. J Laiho, A Wacher, T Novosad, Radio Network Planning and Optimization for UMTS, 1 and 2 th edn. (Wiley \& Sons Ltd., New York, 2002)

doi:10.1186/1687-1499-2012-342

Cite this article as: Lorincz et al:: Impact of service rates and base station switching granularity on energy consumption of cellular networks. EURASIP Journal on Wireless Communications and Networking 2012 2012:342

\section{Submit your manuscript to a SpringerOpen ${ }^{\odot}$ journal and benefit from:}

- Convenient online submission

- Rigorous peer review

- Immediate publication on acceptance

- Open access: articles freely available online

- High visibility within the field

- Retaining the copyright to your article

Submit your next manuscript at $>$ springeropen.com 